\title{
Main Carotenoids Produced by Microorganisms
}

\author{
Sonia Martínez-Cámara ${ }^{1}$, Ana Ibañez ${ }^{2}$, Sara Rubio ${ }^{1}$, Carlos Barreiro ${ }^{3,4, * \mathbb{C}}$ and José-Luis Barredo ${ }^{1}$ \\ 1 Curia. Parque Tecnológico de León. C/Andrés Suárez s/n, 24009 León, Spain; \\ Sonia.Martinez@curiaglobal.com (S.M.-C.); Sara.Rubio@curiaglobal.com (S.R.); \\ JoseLuis.BarredoFuente@curiaglobal.com (J.-L.B.) \\ 2 Instituto de Investigación de la Viña y el Vino, Escuela de Ingeniería Agraria, Universidad de León, \\ 24009 León, Spain; aibas@unileon.es \\ 3 Área de Bioquímica y Biología Molecular, Departamento de Biología Molecular, Universidad de León, \\ 24071 León, Spain \\ 4 INBIOTEC (Instituto de Biotecnología de León), Avda. Real 1-Parque Científico de León, 24006 León, Spain \\ * Correspondence: c.barreiro@unileon.es
}

check for updates

Citation: Martínez-Cámara, S.; Ibañez, A.; Rubio, S.; Barreiro, C.; Barredo, J.-L. Main Carotenoids Produced by Microorganisms. Encyclopedia 2021, 1, 1223-1245. https://doi.org/10.3390/ encyclopedia1040093

Academic Editor: Fabrizio Araniti

Received: 9 October 2021

Accepted: 15 November 2021

Published: 19 November 2021

Publisher's Note: MDPI stays neutral with regard to jurisdictional claims in published maps and institutional affiliations.

Copyright: (C) 2021 by the authors. Licensee MDPI, Basel, Switzerland. This article is an open access article distributed under the terms and conditions of the Creative Commons Attribution (CC BY) license (https:// creativecommons.org/licenses/by/ $4.0 /)$.
Definition: Carotenoids are the pigments present in plants, animals, and microorganisms which are responsible for a broad variety of colors found in nature. Their capacity as antioxidants mainly established their marketable success as health, food, and feed supplements, and cosmetics components. Currently, chemical synthesis dominates the worldwide market; however, due to the high biological value of natural carotenoids, the production scheme is moving towards microbial production as a profitable alternative.

Keywords: fungi; bacteria; algae; carotenoids; carotene; xanthophyll; astaxanthin; beta-carotene; lutein; lycopene; zeaxanthin; canthaxanthin

\section{Introduction}

The simplest way to understand what carotenoids are is to look for colors in living organisms in a natural environment. Those reddish, orange, or yellowish pigments observed in living (micro)organisms are mainly carotenoids. They are one of the most widespread and ubiquitous lipid-soluble and non-nitrogenous pigments. Carotenoids form a subfamily of isoprenoids (also named terpenoids), which result in a diverse group of secondary metabolites. A prevalent example of this is the autumn colors and hues of trees and bushes. Other common examples of carotenoids include the orange-red condiment and food coloring annatto (derived from seeds of the achiote tree (Bixa Orellana)), petals, pollen (e.g., saffron), fruits (e.g., papaya, mandarins, oranges), vegetables (e.g., paprika, tomato), roots (e.g., carrots), animal tissues (e.g., salmonid and goldfish skin, flamingo and canary plumage, invertebrate exoskeletons), and animal products (e.g., egg yolks) (Figure 1) [1-4].

Based on their oxygenation status, carotenoids can be divided in two main groups: (i) oxygenated molecules (oxycarotenoids) and (ii) non-oxygenated molecules. On the one hand, oxycarotenoids including carbonyl, carboxylic acid, ester, epoxy, hydroxy and methoxy groups are the xanthophylls (e.g., astaxanthin $\left(\mathrm{C}_{40} \mathrm{H}_{52} \mathrm{O}_{4}\right)$, canthaxanthin $\left(\mathrm{C}_{40} \mathrm{H}_{52} \mathrm{O}_{2}\right)$, lutein $\left(\mathrm{C}_{40} \mathrm{H}_{56} \mathrm{O}_{2}\right)$ or zeaxanthin $\left.\left(\mathrm{C}_{40} \mathrm{H}_{56} \mathrm{O}_{2}\right)\right)$. On the other hand, those strictly non-oxygenated molecules (hydrocarbons) are the carotenes $\left(\mathrm{C}_{40} \mathrm{H}_{56}\right)$ (e.g., lycopene, $\alpha$-carotene, $\beta$-carotene) (Figure 2) [2,3,5].

Nowadays, 722 organisms have been described as the source of the 1204 natural carotenoids currently defined in the Carotenoid DataBase (http:/ / carotenoiddb.jp (accessed on updated: September 2020) [6,7]. They are naturally produced by photosynthetic species (plants, algae, and cyanobacteria), some groups of fungi and some nonphotosynthetic bacteria $[4,8,9]$. Although it is generally recognized that humans and animals are not able to produce their own carotenoids, the genome sequencing of the pea 
aphid (Acyrthosiphon pisum) detected carotenoid biosynthetic genes due to horizontal gene transfer from fungi $[10,11]$.

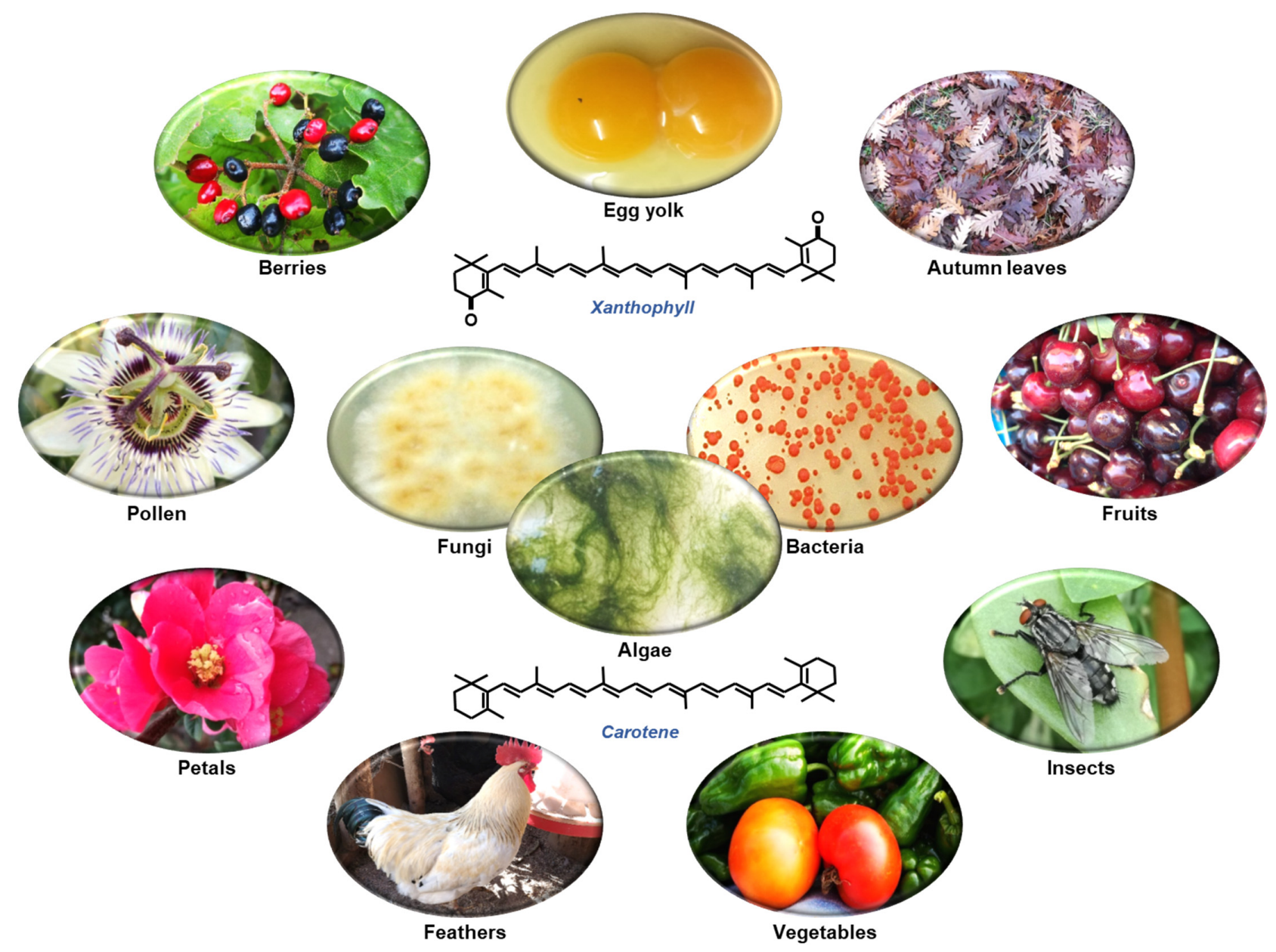

Figure 1. Examples of different colored structures from natural environments where diverse carotenoids can be found. The center panel presents some of the most common carotenoid producers (fungi, algae, and bacteria) and the structure of a xanthophyll (upper: canthaxanthin) and a carotene (lower: $\beta$-carotene).<smiles>CC(C)=CCC/C(C)=C/C=C/C(C)=C/C=C/C(C)=C/C=C/C=C(C)/C=C/C=C(C)/C=C/C=C(\C)CCC=C(C)C</smiles>

Figure 2. Acyclic $\mathrm{C}_{40} \mathrm{H}_{56}$ model structure of a carotenoid molecule.

\subsection{Brief History of Carotenoids Discovery and Production}

Carotenoids are taxonomically widespread and serve as pigments in plants and animals, and are the reason for the diverse and intense colors present in nature (Figure 1) [12]. Because of this colorful characteristic, these compounds were one of the earliest studied phytochemicals [13], leading to the study of carotenoid pigments that began in the nineteenth century and spanning 200 years. This history can be divided into four periods, as Otto Isler indicated in his book entitled Carotenoids, in 1971 [14].

Beginning in the 19th century (first period), the core of carotenoid analysis was the isolation of the pigments and their characterization through their light absorption measurements, although their structures were still widely unknown [15]. Henri Braconnot (1780-1855) was likely in charge of the first research on carotenoids in 1817, which was car- 
ried out in paprika (Capsicum annuum). More than a hundred years later (1927), a pigment from paprika was purified in its crystalline form under the name of capsanthin [9]. In 1818, Aschoff isolated an apocarotenoid named crocin (from the word "crocos", which means saffron in German [16]). The apocarotenoids are carotenoid cleavage products as a result of the activity of specific carotenoid cleavage oxygenases $[17,18]$. Crocin is the chemical ingredient primarily responsible for the saffron color (Crocus sativus) [16,19]. A few years later, in 1823, the research on crab (Brachyura) developed by Goebel suggested for the first time the presence of carotenoids in animals. However, Heinrich Wackenroder (1798-1854) reached the best-recognized milestone in 1831 because of research on carrots (Daucus carota L.). He isolated and described for the first time the $\beta$-carotene as part of his analysis of carrot juice when he searched for an effective anthelminthic drug [20]. Subsequently, in 1837, the Swedish chemist Jöns J. Berzelius (1779-1848) defined the xanthophyll present in autumn leaves. Later, lycopene was isolated from berries of Tamus communis by Hartsen in 1873. A few years later, in 1903 Schunk gave its name (lycopene) when noticed that this tomato pigment had a different absorption spectrum than carrot carotenes [7,20-23].

Following this first period (19th century) of carotenoid research, which focused on their isolation, the second period (1900-1927) was based on the determination of the empirical formula of carotenoids. These tentative efforts to discover carotenoid's role in photosynthesis were also capital [14]. Because of the different carotenoid characterizations, Richard Willstätter (1872-1942) and Walter Mieg established the empirical formula of $\beta$-carotene $\left(\mathrm{C}_{40} \mathrm{H}_{56}\right)$ in 1907 [24]. In 1919, Harry Steenbock (1886-1967) observed growth promoting activity due to the carotenoids found in colored vegetables. He noticed how the yellow corn and yellow vegetables (e.g., sweet potato, carrots), in contrast to white vegetables (e.g., potato, parsnip), decreased the effect of lacking vitamin A [25]. Ten years later, Hans von Euler (1873-1964) and Paul Karrer (1889-1971) defined $\beta$-carotene as a good growth factor closely related to vitamin A (retinol). Later, the $\beta$-carotene and vitamin A structures were elucidated in 1930-1931 by Karrer, who received the Nobel Prize in Chemistry in 1937 "for his investigations on carotenoids, flavins and vitamins A and B2" (the Nobel Prize: www.nobelprize.org, accessed on August 2021) [7,14].

The findings on vitamin A opened up the third period of carotenoid analysis. The provitamin A ( $\beta$-carotene) concept was the core of this third carotenoid period (1928-1949). The idea of provitamins (molecules able to be transformed into vitamins by the organism) was a completely new concept, which resulted in great scientific and commercial significance. The elucidation of structural formula and the development of synthesis methods also fueled this third period [14]. This resulted in the number of known naturally occurring carotenoids growing from 15 to about 80 over 15 years (1933-1948). The structures of around 35 of these pigments were defined too. In 1947, the first chemical synthesis of crystalline vitamin A was announced by Isler and co-workers [26], which initiated the development of different industrial manufacturing procedures. In 1950, several groups allowed the total synthesis of $\beta$-carotene, which opened next period of carotenoid research.

The fourth period (1950-1990) increased the number of new carotenoids exponentially and led to extraordinary advances in carotenoid chemical synthesis, and their absolute configuration determination were reached. Thus, in 1960, Rhodia Inc. begun the production of methylheptenone from isoprene; BASF obtained iso-methylheptenone from isobutylene; Glidden Co. was able to synthesize citral from turpentine oil via myrcene [7]. Nowadays, the $\mathrm{C}_{40}$-carotenoids produced by industrial synthesis are reached by double Wittig condensation of symmetrical structures (e.g., identical end groups). However, just five out of the several hundred naturally occurring carotenoids (lycopene, canthaxanthin, astaxanthin, $\beta, \beta$-carotene, and zeaxanthin) and three apocarotenoids ( $\beta$-apo- $8^{\prime}$-carotenal, $\beta$-apo- $8^{\prime}$ carotenoate, and citranaxanthin) are synthetically produced at industrial scales $[27,28]$. Only 50 carotenoids are valuable in human nutrition and up to 20 of them are typically detected in human blood and tissues, which come from the diet [3,29]. BASF SE, Kemin Industries, DSM Animal Nutrition, Novus International Inc, Biochem Products B.V., and Allied Biotech Corporation are the main worldwide players of the feed carotenoids market, 
which accounted for $81 \%$ of the overall revenue in 2020 (www.mordorintelligence.com, accessed on August 2021).

The need for commercial production of natural pigments boosted intensive research on the microbial biosynthesis of carotenoids, which can be considered the fifth period of carotenoids research (1991 to present). $\beta$-carotene and astaxanthin, for example, are extensively studied and industrially produced by microbial fermentation $[3,28,30]$. However, the screening of new producers of carotenoids (algae, bacteria, yeast and fungi), the development of fermentation processes or the use of genetic engineering or synthetic biology methodologies (e.g., search and use of genes involved in carotenoid biosynthesis, storage and catabolism) mark this fifth period [3,31-33].

\subsection{What Are Carotenoids?}

Based on their chemical characteristics, carotenoids are lipophilic compounds insoluble in water, which contain a chromophore. They comprise a long polyene central chain of conjugated double bonds (with a maximum absorbance of 400-500 nm), which is the reason for their characteristic yellow to reddish colors [3]. Following the IUPAC's rule 1 about the definition of classes of compounds: "carotenoids are a class of hydrocarbons (carotenes) and their oxygenated derivatives (xanthophylls) consisting of eight isoprenoid units joined in such a manner that the arrangement of isoprenoid units is reversed at the centre of the molecule so that the two central methyl groups are in a 1,6-positional relationship and the remaining nonterminal methyl groups are in a 1,5-positional relationship. All carotenoids may be formally derived from the acyclic $\mathrm{C}_{40} \mathrm{H}_{56}$ structure, having a long central chain of conjugated double bonds, by (i) hydrogenation, (ii) dehydrogenation, (iii) cyclization, or (iv) oxidation. or any combination of these processes" (https://www.qmul.ac.uk/sbcs/iupac/carot/car1t7.html\#p2, accessed on August 2021) (Figure 2) [2].

On the other hand, if the number of carbons are to be taken into account, the carotenoids, following the Carotenoid DataBase (http://carotenoiddb.jp, accessed on August 2021; https:/ / www.qmul.ac.uk/sbcs/iupac/carot/car1t7.html\#p2, accessed on August 2021) can be divided into: (i) $\mathrm{C}_{30}$ (37 carotenoids; e.g., 4, $4^{\prime}$-diapolycopene), (ii) $\mathrm{C}_{40}$ (1121 carotenoids; e.g., lycopene), (iii) $\mathrm{C}_{45}$ (13 carotenoids; e.g., nonaflavuxanthin: intermediate in the biosynthesis of decaprenoxanthin $\left(\mathrm{C}_{50}\right)$ by Corynebacterium glutamicum $)$ and (iv) $\mathrm{C}_{50}$ (33 carotenoids; e.g., haloxanthin).

\subsection{Biosynthetic Pathways of Carotenoids}

Carotenoid biosynthetic pathways have been extensively studied over the past years. The starting molecule from which all carotenoids are synthesized is phytoene, a C40 colorless carotenoid. First, two molecules of geranylgeranyl diphosphate (GGPP) are condensed by the enzyme phytoene synthase (CrtYB) to produce phytoene. GGPP molecules are in turn synthesized by the condensation of dimethylallyl pyrophosphate (DMAPP) and three molecules of isopentenyl pyrophosphate (IPP), by means of the enzyme GGPP synthase (CrtE). Mainly in eukaryotes, these precursor molecules derive from the mevalonate pathway (MEV), whilst in prokaryotes and plants they derive from the methyl-erythritol phosphate pathway (MEP), also known as the non-mevalonate pathway [34].

Consequently, the enzyme phytoene desaturase (CrtI) catalyzes the transformation of phytoene into lycopene by introducing four double bonds. This enzyme can conduct further desaturation, synthesizing linear carotenoids, such as neurosporene or 3,4-didehydrolycopene.

In fungi (e.g., Xanthophyllomyces dendrorhous, Puccinia graminis [35,36]), the gene crtYB encodes a bifunctional enzyme that can perform as a phytoene synthase, as previously mentioned, and as a lycopene cyclase. The latter enzymatic activity is able to convert the acyclic ends of lycopene into $\beta$-rings, and generates carotenoid diversity, by producing $\beta$-carotene and $\gamma$-carotene. Subsequently, ketolation and hydroxylation reactions occur in order to synthesize other carotenoids (Figure 3). Depending on the microorganism, some carotenoids can be synthesized by enzymes encoded by different genes [37]. 
$\beta$-carotene hydroxylase is an enzyme encoded by the $\mathrm{crtZ}$ gene, which is able to hydroxylate $\beta$-carotene to form $\beta$-cryptoxanthin, and further add another hydroxy group to finally synthesize zeaxanthin.

Canthaxanthin is produced by the transformation of two methylene groups located in the $\beta$-ionone rings of $\beta$-carotene into keto groups. This reaction is carried out by the enzyme $\beta$-carotene ketolase $(\mathrm{CrtW})$, which initially adds a keto group to $\beta$-carotene, forming echinenone, and afterwards synthesizes canthaxanthin by adding an extra keto group [38].

Furthermore, astaxanthin is formed by the addition of 4-keto groups and 3-hydroxy groups to the molecule of $\beta$-carotene, by means of the enzyme astaxanthin synthetase (CrtS), helped by a cytochrome $\mathrm{P} 450$ reductase (CrtR). These enzymes are naturally present in some microorganisms, such as X. dendrorhous [39]. Moreover, the biosynthesis of astaxanthin in other microorganisms has been described by means of the enzymes $\beta$-carotene hydroxylase and $\beta$-carotene ketolase, encoded by the genes $c r t Z$ and $c r t W$, respectively [40].

The lutein biosynthetic pathway is mainly present in plants. Lutein can be synthesized from lycopene through the action of two lycopene cyclases (AtLCYe and AtLCYb) and two hydroxylases (AtCYP97A and AtCYP97C). The production of lutein has been observed in a strain of Synechocystis sp. transformed with the previously mentioned genes [34]. 


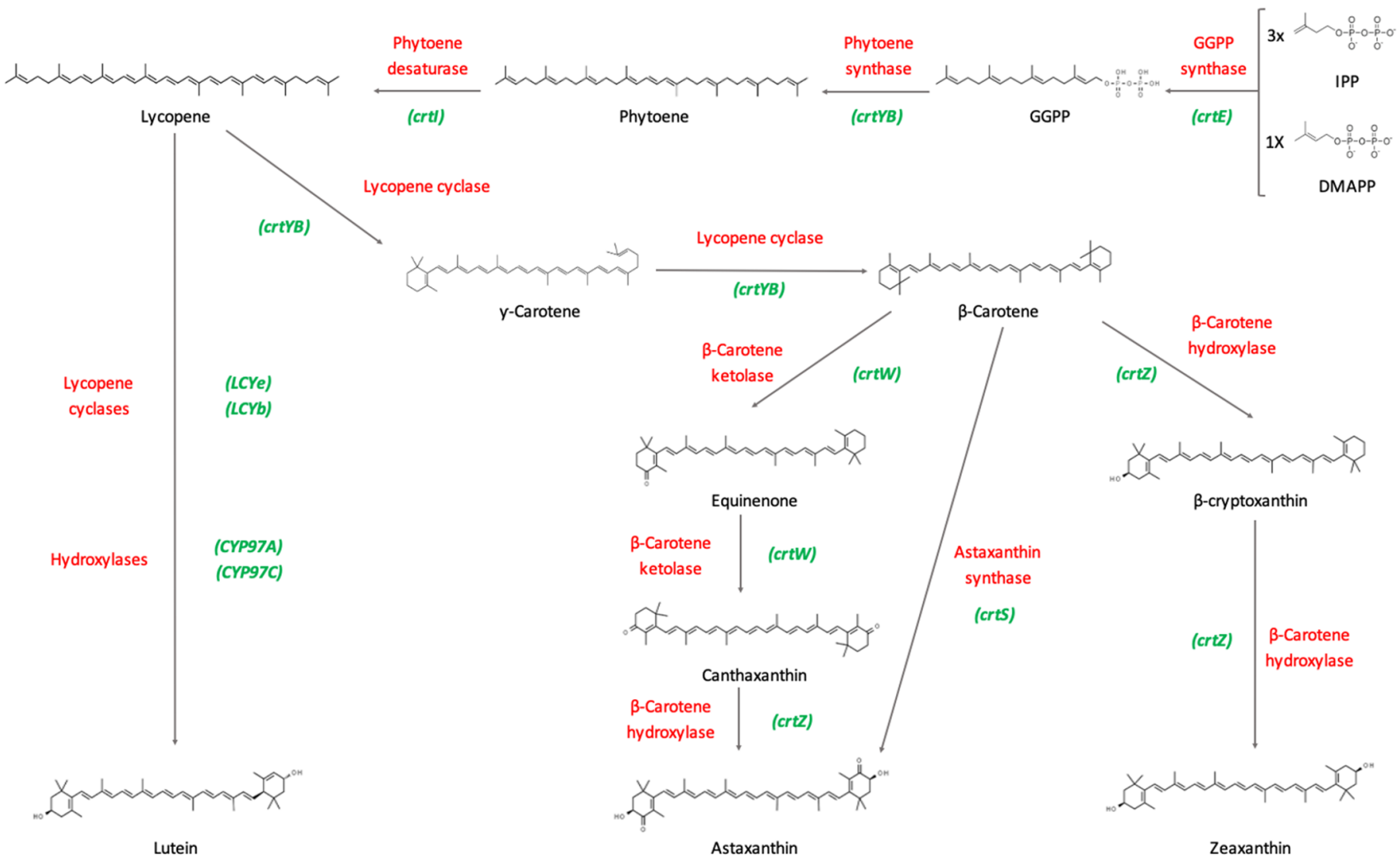

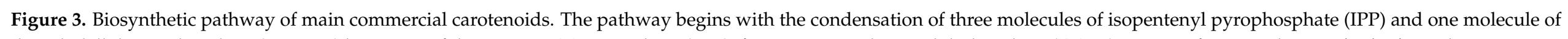

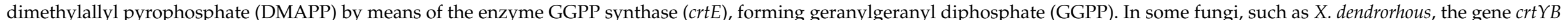

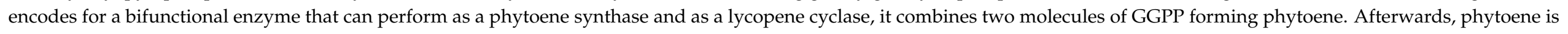

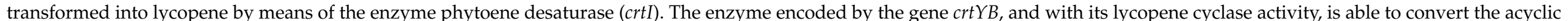

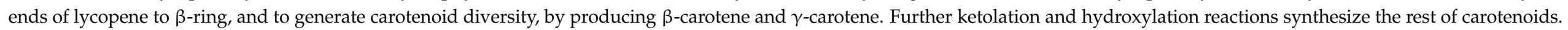

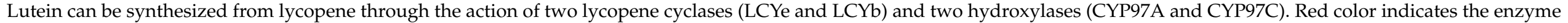
name, whereas green color shows the gene names. This figure is based on Rodríguez-Sáiz and co-workers and Barreiro and co-workers [8,39]. 


\section{Carotenoids Market}

As mentioned earlier, chemically-synthesized carotenoids dominate the market. Natural carotenoids obtained from plants, animals, and microorganisms are still limited. They can be synthetically produced using low-cost chemicals without living organisms involved in the process, which satisfy the majority of the worldwide market demand $(>73 \%$ of the global market in 2013). This is particularly true in developing regions, such as the Asia-Pacific market. However, naturally extracted carotenoids are becoming increasingly accepted by the consumer market, resulting in a higher demand of natural products. This holds especially true in the European Union and North America, markets which are limiting the use of harmful additives in food and feed. Besides, these natural carotenoids are preferred by the health market because of their lower potential for toxic effects, in contrast with synthetic ones, and due to their higher biological properties (e.g., healthier, more favorable cis/trans isomer mixtures). The health-promoting properties of those chemically obtained are lower, which results in a less valuable, less desirable product. The market intelligence and advisory firm, Mordor Intelligence (www.mordorintelligence.com, accessed on August 2021), prices synthetic carotenoids from $\$ 250$ to $\$ 2000 / \mathrm{kg}$, whereas natural carotenoids are sold between $\$ 350-\$ 7500 / \mathrm{kg}$, which highlights the higher relative value of natural versus synthetic carotenoids. As a result, the industry is being stimulated by means of green solutions and biotechnological applications of microbial and plant sources [3,41-43].

The worldwide market of carotenoids is around $\$ 1.5$ billion. Ram and co-workers in 2020 [44], based on an Andrew McWilliams' report for the BCC Research company entitled "The Global Market for Carotenoids" (www.bccresearch.com, accessed on August 2021), dated 2017 for this revenue. However, the market research report of the data provider company MarketsandMarkets (www.marketsandmarkets.com, accessed on August 2021), defined the year 2019 as the proper date. Besides, MarketsandMarkets predicts the carotenoid market to reach $\$ 2.0$ billion by 2026, whereas BCC Research established this market value in 2020. Either way, it is clear that the global carotenoids market is on the brink of reaching a value of $\$ 2.0$ billion, which is more than 2.5-fold higher than the \$766 million estimated in 2011, and double that of the \$919 million projected in 2015 [43]. Fortune Business Insights (www.fortunebusinessinsights.com, accessed on August 2021) estimates the global carotenoids market had a size of $\$ 1.44$ billion in 2019, and anticipated reaching $\$ 1.84$ billion by 2027. Even though estimation of the global market seems difficult, the commercial significance of carotenoids as part of the biological and chemical products is highly relevant due to their uses (food, feed, pharma, cosmetics) [3].

When a detailed analysis is done of the main carotenoids present in the market, the two that are the most common ones industrially produced are astaxanthin and $\beta$-carotene. Global market size of astaxanthin was estimated at $\$ 1.0$ billion in 2019 by the Indo-American market research and consulting company Grand View Research (www.grandviewresearch. com, accessed on August 2021). However, a new research report of the Global Market Insights Inc (www.globenewswire.com, accessed on August 2021) predicted the astaxanthin market would have a revenue of $\$ 950$ million by 2027 . Besides, they predicted that the market from synthetic astaxanthin sources reached \$200 million in 2020.

The $\beta$-carotene worldwide market was estimated by the MarketsandMarkets company (www.marketsandmarkets.com, accessed on August 2021) to be around $\$ 510$ million by 2020, and may increase up to $\$ 520$ million in 2025. However, Global Market Insights Inc (www. gminsights.com, accessed on August 2021) established the $\beta$-carotene market to be around $\$ 520$ million in 2020, and projected $\$ 720$ million in 2027. Regarding volume production, the worldwide market research and counselling firm Credence Research (www.credenceresearch. com, accessed on August 2021) reported 343.72 tons in 2014 and a projected 423.65 tons by 2022. The company Research and Markets (www.researchandmarkets.com, accessed on August 2021) presents similar figures, estimating a market demand of 371.56 tons in 2017, reaching 451.81 tons by 2025 . 


\section{Relevance of Carotenoids}

Other than the stunning visual colors of carotenoids, what is their natural role of these compounds in nature?

Carotenoids avoid oxidative damage (antioxidant function) of cells and cellular organelles by quenching the scavenging singlet oxygen molecules, peroxy radicals, and other toxic oxygen species. This ability as quenchers of oxidative species explains their role in nonphotosynthetic organisms as photoprotectors. However, individual carotenoids additionally act through other mechanisms (e.g., $\beta$-carotene is pro-vitamin A, lutein/zeaxanthin are eye macular pigments) [45]. Secondly, photosynthesis is also a process where carotenoids are involved as working photoprotectors of the photosynthetic molecules, extending the range of light absorbed by photosynthetic systems. Besides this, they have a highly relevant ecological role attracting pollinators and seed dispersal agents [9].

From an industrial point of view, the oxidative protection capacity of the carotenoids has caught the attention of medical research studies associated with (i) chronic diseases (e.g., cardiovascular diseases, immune activation, neurological disorders, cognitive performance, diabetes, bone health, cancer); and (ii) degenerative pathogenesis (e.g., Alzheimer, Parkinson). Additionally, new lifestyle trends have increased the demand for nutritional supplements, such as carotenoids, which offer health benefits. In cosmetics, carotenoids block the naturally occurring effects of ROS (reactive oxygen species) on skin cells. Finally, intensive farming and aquaculture need feed supplementation that mimics the natural pigments present in different animals (e.g., salmon, trout, crustaceans) and tissues (e.g., egg yolks, skin, legs, fat, beaks, feathers) [3,13,43,45-50].

Today, amongst all existing carotenoids, six of them are considered industrially relevant: astaxanthin, $\beta$-carotene, canthaxanthin, lutein, lycopene, and zeaxanthin [3].

\subsection{Astaxanthin}

Astaxanthin (3, $3^{\prime}$-dihydroxy- $\beta, \beta$-carotene- $4,4^{\prime}$-dione) is a red-orange pigment with a hydroxyl and a ketone group at both ends of the molecule, which makes it a superior antioxidant to most of the other carotenoids (Figure 3).

Astaxanthin is the main carotenoid used as a feed additive for salmonids and crustaceans grown in captivity to provide the pink color that is characteristic of their flesh [51]. Additionally, it is a valuable compound due to its powerful antioxidant properties, and it has also emerged as an interesting compound due to a variety of beneficial health effects. These include cardiovascular, anticancer, antidiabetic, anti-inflammatory, and immunostimulation, as well as cardiovascular, neuro-, ocular-, and skin-protective effects [52].

Roughly $95 \%$ of astaxanthin is produced by chemical synthesis. It can also be obtained from natural sources like plants or microorganisms. Chemical astaxanthin has a lower price in the market (around $\$ 1000 / \mathrm{kg}$ ) compared to the natural one, and it is mostly used in aquaculture. Although synthetic astaxanthin is also approved for human use, there is increasing demand for astaxanthin from natural sources. Currently, large scale production of biological astaxanthin is carried out through cultivation of the microalgae Haematococcus pluvialis, and from the yeast $X$. dendrorhous (Phaffia rhodozyma) [8,53]. Astaxanthin can also be produced by fermentation of the marine bacteria Paracoccus carotinifaciens. Thus, Panaferd-AX, a powder obtained by drying cells of $P$. carotinifaciens, contains approximately $2 \%$ astaxanthin, and is approved in the European Union and in the United States for salmon and trout farming (https:/ / www.eneos.co.jp/english/products/function/astaxanthin/, accessed on September 2021).

The major astaxanthin producers are DSM Nutritional Products (AstaSana ${ }^{\mathrm{TM}}$ ), BASF (Lucantin ${ }^{\circledR}$ Pink) and NHU (Essention Pink 10\%) [3].

AstaSana $^{\mathrm{TM}}$, commercialized by DSM Nutritional Products, is a synthetic astaxanthin (5\%) dispersed in a matrix of modified food starch and glucose syrup and stabilized with antioxidants. It is bio-equivalent to astaxanthin found in nature. It is a violet, fine granular powder, dispersible in cold water, used as a dietary supplement for human use. (https://www.dsm.com/human-nutrition/en/products/carotenoids/astasana.html, 
accessed on September 2021). DSM also commercializes astaxanthin as a feeding additive for salmonid pigmentation (Carophyl Pink ${ }^{\circledR}$ )

Lucantin ${ }^{\circledR}$ Pink, commercialized by BASF, is sold for improving pigmentation in aquaculture. It is distributed in different formats: dark-violet/red microcapsules of powder, with $10-20 \%$ astaxanthin content, in a matrix of gelatins, sucrose, syrup, corn, lactose and/or soy, and stabilized with different compounds (https:/ / nutrition.basf.com/global/ en/animal-nutrition/products/lucantin-pink.html, accessed on September 2021).

Essention Pink $10 \%$ is sold for animal feed as violet-brown to violet-red microcapsules formulated with corn-starch, sucrose, gelatin, glycerin, antioxidants ( $\alpha$-tocopherol and ascorbic acid), and anti-caking agents (silicic acid) (https:/ /www.nhu-eu.com/products/ feed.html, accessed on September 2021).

\section{2. $\beta$-Carotene}

$\beta$-Carotene $(\beta, \beta$-carotene) is a red to orange pigment that consists of 40 carbon atoms in a core structure of conjugated double bonds substituted with two $\beta$-ionone rings (Figure 3). It is found naturally in a variety of fruits and vegetables such as carrots (65-210 $\mu \mathrm{g} / \mathrm{g}$ fresh weight basis), apricots (25-170 $\mu \mathrm{g} / \mathrm{g}$ fresh weight basis), coriander leaves (586 $\mu \mathrm{g} / \mathrm{g}$ dry weight basis), or pumpkin (10-172 $\mu \mathrm{g} / \mathrm{g}$ fresh weight basis) [54,55].

B-Carotene is commercially used as a colorant in the food, feed, cosmetics, and pharmaceutical industries. It is also used as a pro-vitamin A supplement to achieve the recommended $\beta$-carotene dietary intake [56]. It has an important role in human health, as a precursor of vitamin $\mathrm{A}$, along with $\alpha$-carotene and $\beta$-cryptoxanthin. This vitamin is important for many functions of the human body. It is particularly significant for vision, normal growth and development, and immune function. During pregnancy, vitamin A plays an essential role in healthy embryonic development. In addition, other properties have been attributed to $\beta$-carotene, such as antioxidant activity, protection against UVinduced erythema and photosensitivity, or some types of diabetes prevention [56-58]. In animals, $\beta$-carotene has been described as improving reproductive efficiency in dairy cattle $[59,60]$.

This pigment is mostly produced by chemical synthesis and it is offered in a wide range of formats for human healthcare (Lucarotin ${ }^{\circledR}, \mathrm{BASF}$; Quali ${ }^{\circledR}$-Carotene, DSM Nutritional Products) and as a feed supplement (ROVIMIX ${ }^{\circledR} \beta$-carotene, DSM Nutritional Products). It can also be obtained by extraction from plants or algae such as Dunaliella salina (Betatene ${ }^{\circledR}$, BASF), or by fermentation of the fungus Blakeslea trispora (Lucarotin ${ }^{\circledR}$ B, BASF; CaroCare ${ }^{\circledR}$, DSM Nutritional Products) for human use.

\subsection{Canthaxanthin}

Canthaxanthin ( $\beta, \beta$-Carotene- $4,4^{\prime}$-dione) is an orange-red to red xanthophyll. This molecule has nine conjugated double bonds, terminated by two oxo substituents at positions 4 and $4^{\prime}$ of the $\beta$-ionone backbone (Figure 3 ).

It is widely distributed in nature and commercialized in some regions for its coloring properties. Initially, it was isolated from an edible chanterelle mushroom (Cantharellus cinnabarinus) [61], and subsequently has been identified in a vast variety of species. It is present in fungi such as Aspergillus carbonarius ( $20.3 \%$ DW), microalgae, Botryococcus braunii (46\% DW), and bacteria as Dietzia sp. (90-92\% of total carotenoids) [41,62-65]. Canthaxanthin can be found in animals such as red-feathered birds (e.g., flamingos), fish flesh (e.g., carps), and egg yolk [37].

Potential health benefits of canthaxanthin include antioxidant properties, free radical scavenging, and gene regulatory properties. However, the mechanisms by which canthaxanthin may mediate potential health benefits are not totally understood, and further investigation shall be carried out. However, there is increasing experimental evidence suggesting that canthaxanthin may affect gap junction communication and immune function [62]. In contrast, it has been described that a high intake of canthaxanthin could cause ocular lesions such as macula crystallization and retinopathy. This effect has been 
associated with intake of unsafe tanning pills (FDA (U.S. Food and Drug Administration), http:/ /www.fda.gov/Cosmetics/ProductsIngredients/Products/ucm134217.htm, accessed on September 2021) [66].

Canthaxanthin is widely used in aquaculture and poultry as a feed colorant. In aquaculture, it is used for coloring rainbow trout and salmon flesh, administered frequently with astaxanthin. In poultry industry, it is used in the laying hen's diet for coloring egg yolks in combination with other carotenoids to obtain an optimal pigmentation, and in chicken to color the skin (Lucatin ${ }^{\circledR}$ Red, BASF; Carophyll ${ }^{\circledR}$ Red, DSM Nutritional Products). It is also used to feed ornamental birds and fishes to provide a brighter and healthier color to the feathers and the flesh.

In the food industry, canthaxanthin is approved as an additive in the EU (E161g) for coloring the "saucisse de Strasbourg", as well as coloring matter in feeding stuffs. In contrast to other carotenoids, canthaxanthin is not used as a nutraceutical $[62,67]$.

Commercial canthaxanthin can be found in diluted or stabilized forms in order to prevent oxidation of the compound, including suspensions or solutions in edible fats or oils, emulsions, or water-dispersible powders $[62,67]$. Nowadays, canthaxanthin is produced by chemical synthesis. Alternative ways of manufacturing this pigment are being explored in order to find a cost-efficient and more environmentally friendly process that meets market requirements. These new ways include natural sources such as plants, algae or bacteria, and also synthetic biology for its production in heterologous systems (Escherichia coli, Nostoc sp., Mucor circinelloides) [61].

\subsection{Lutein}

Lutein $\left[\left(3 R, 3^{\prime} R, 6^{\prime} R\right)-\beta, \varepsilon\right.$-Carotene-3, $3^{\prime}-$ diol $]$ is a yellowish xanthophyll (Figure 3$)$. It is the main carotenoid found in human serum, human milk, and in a variety of dietary fruits and vegetables such as mango $(31.7 \mu \mathrm{g} / \mathrm{g}$ fresh weight basis), papaya $(237 \mu \mathrm{g} / \mathrm{g}$ fresh weight basis), watermelon (172 $\mu \mathrm{g} / \mathrm{g}$ dry weight basis), spinach $(775.8 \mu \mathrm{g} / \mathrm{g}$ dry weight basis), kale (65 $\mu \mathrm{g} / \mathrm{g}$ fresh weight basis), chicory ( $59.1 \mu \mathrm{g} / \mathrm{g}$ fresh weight basis) or broccoli (28 $\mu \mathrm{g} / \mathrm{g}$ fresh weight basis) [54]. In nature, lutein is most abundant in petals of yellow marigold (Tagetes erecta L.). This plant is the lutein source at industrial scales.

Lutein is best known for its role in visual health. Together with zeaxanthin and mesozeaxanthin, these are the only carotenoids found in both the macula and lens of human eye. Several studies suggest that lutein and zeaxanthin are important for delaying and reducing age-related macular degeneration, and reduce the risk of cataracts. These carotenoids absorb light from the visible spectra, protecting the retina and the lens from potential damage caused by light exposure. Besides, these macular carotenoids protect the eye from oxidative stress and free radicals due to their antioxidant properties [68-70]. Beneficial properties of lutein are not restricted to visual health; it is also a potent antioxidant that protects skin from photo-oxidative damage, since it filters near-UV high-energy blue light [71,72]. It has also been described for having additional benefits for human health such as preventing cancer, cardiovascular disease, type 2 diabetes, or improving cognitive function $[58,73,74]$, although some authors claim that additional studies should be carried out in order to generate enough evidence before deciding whether lutein should be clinically used or not [48].

In human nutrition, lutein is commercialized as a colorant, but it is mainly used due to its antioxidant properties and to reduce risk of cataracts and macular degeneration. The company Kemin Industries commercializes it under the trademark of FloraGLO ${ }^{\circledR}$. The same product, FloraGLO ${ }^{\circledR}$, is sold by DSM Nutritional Products in a variety of formats for optimized bioavailability, stability and low extrusion loses: as a powder or as a fluid, in different concentrations, alone or mixed with zeaxanthin. The company BASF commercializes lutein under the trademark Xangold ${ }^{\circledR}$ Lutein.

Lutein is also used in poultry feed mainly to color eggs and to enhance chickens' skin with a visual vigorous color. It also brings health benefits to chickens supplemented with this carotenoid. It is generally administered together with other orange-red xanthophylls 
to obtain an intense yellow hue, generally canthaxanthin [75]. Nowadays, lutein's presence in the egg yolk industry is shared with zeaxanthin and $\beta$-apo- $8^{\prime}$-carotenoic acid (apo-ester). The latter provides a similar yellow hue to egg yolks as lutein and zeaxanthin, but has a higher deposition rate than both of them, making it a more efficient pigment. Thus, it is the preferred choice for providing yellow pigmentation to yolks [76] (https:/ /www.dsm. com/anh/en_US/feedtalks/feedtalks/eggyolk-pigmentation-guidelines.html, accessed on September 2021).

Lutein is industrially produced by extraction from yellow marigolds [71,76]. This flower extract composition consists mainly of all-trans and cis isomers of lutein and esters of lutein $(88 \%)$, and all-trans and cis isomers of zeaxanthin (5\%), although this proportion may vary depending on the source extracted [77].

Some of the key manufacturers of lutein are DSM Nutritional Products, Kemin Industries, Allied Biotech Corporation, BASF and Chr. Hansen (https: / www.gminsights.com/ industry-analysis/lutein-market, accessed on September 2021).

\subsection{Lycopene}

Lycopene $(\psi, \psi$-Carotene) is an open-polyene chain which lacks the $\beta$-ionone ring structures found in $\beta$-carotene (Figure 3 ). It is a red carotenoid synthesized naturally by some plants and microorganisms mostly in the isomer all-trans. The best known dietary intake of lycopene in humans is from tomatoes, but it can also be found at equivalent levels in other fruits such as persimmon, pink guava, or watermelon [55].

Lycopene is widely used as a pigment in the food industry. It is used, for example, in fruit juices and soft drinks, sport drinks, cereals, bread, dairy products, dietary products, and dietary supplements [78]. In addition, there is growing interest in lycopene due to its health promoting properties, such as antioxidant activity that protects DNA, lipids, and proteins from oxidative damage, anti-cancer activity, or cardioprotective activity. Several mechanisms by which lycopene acts against cancer have been described: (i) growth reduction of the cancer cell lines, including those causing prostate cancer; (ii) apoptosis of cancerous cells; (iii) induction of enzymes that protect against carcinogens; (iv) modulation of DNA transcription; (v) reduction of intracellular levels of cholesterol (which has been reported to be important for activation of oncogenes); and (vi) decreasing cytokine levels that promote tumors $[79,80]$.

Cardioprotective effects of lycopene are associated with its antioxidant properties which defends endothelial cells from oxidative damage, its anti-inflammatory activity which could be useful in vascular inflammatory disorders, or its ability to reduce cholesterol and triglycerides levels, among others [81,82]. However, an evaluation conducted in 2011 by the European Food Safety Authority (EFSA) concluded that there was no causeeffect relationship between consumption of lycopene and putative health benefits such as protection of DNA, proteins, and lipids from oxidative damage, protection of skin from UV-induced damage, contribution to normal cardiac function or maintenance of normal vision [83]. Although there is considerable evidence that lycopene has a beneficial effect on human health, the exact molecular mechanisms of action need to be deciphered.

Commercial lycopene is produced mainly by extraction from natural sources, such as tomato, although it can also be produced by chemical synthesis or by fermentation of the fungus B. trispora [78]. Major players in lycopene market are BASF, DSM Nutritional Products, Lycored, and twenty more companies (https: / / www.researchandmarkets.com/ reports /4425276/lycopene-market-forecast-2020-2025, accessed on September 2021).

For example, Lycored offers natural lycopene obtained from tomato plants (LycoBeads) in different forms: microencapsulated alginate beadlets, gelatin-based, microencapsulated powder, and microencapsulated tablet grade and water dispersible beadlets. It is sold as a dietary supplement. DSM nutritional Products commercializes synthetic crystalline (all-trans) lycopene for human use (Redivivo ${ }^{\circledR}$ ). It is presented in spray granulated powder, or as a fluid suspension for use as a dietary supplement in the food and drink industries. Similarly, the carotenoid manufacturer BASF offers a synthetic lycopene for human use 
under the trademark of Lycovit ${ }^{\circledR}$, offering both a more cost-effective alternative to natural lycopene extracted from tomatoes, and an alternative for artificial azo dyes for applications in beverages, foods, and dietary supplements.

\subsection{Zeaxanthin}

Zeaxanthin $\left(\left(3 R, 3^{\prime} R\right)-\beta, \beta-C a r o t e n e-3,3^{\prime}\right.$-diol $)$ is an isomer of lutein: the two alcohol groups of the molecule differ from each other by the shift of a single double bond (Figure 3 ). It is naturally found in fruits and vegetables such as papaya (14.1 $\mu \mathrm{g} / \mathrm{g}$ fresh weight basis), corn $(6 \mu \mathrm{g} / \mathrm{g}$ fresh weight basis), or spinach $(15.1 \mu \mathrm{g} / \mathrm{g}$ dry weight basis) [54].

Zeaxanthin, together with lutein and meso-zeaxanthin, have been described as having a critical role in visual health. A higher dietary intake of these xanthophylls has been associated with reducing the risk of cataracts and age-related macular degeneration [71,84]. These carotenoids absorb light from the visible spectra, protecting the retina and the lens from potential damage caused by light exposure. Besides, these macular carotenoids protect the eye from oxidative stress and free radicals due to their antioxidant properties [68-70].

Zeaxanthin is commercially used in the food, cosmetic, and pharmaceutical industries as pure formulation or in combination with other carotenoids for its coloring properties, and it is also used as a supplement for its putative beneficial health effects (OPTISHARP ${ }^{\circledR}$, DSM Nutritional Products) [51,84].

In addition to its use as a human food supplement, zeaxanthin, together with lutein and $\beta$-apo- $8^{\prime}$-carotenoic acid (apo-ester), is used in poultry feed, mainly to provide a yellow color to egg yolk, and a visually healthy color to the skin of chickens. It is generally administered together with other orange-red xanthophylls to obtain an intense yellow hue, generally canthaxanthin. Nowadays, the preferred carotenoid for providing a yellow hue to yolk is the apo-ester, due to the fact that it has a higher deposition rate than lutein and zeaxanthin, thus making it a more efficient pigment [76] (https://www.dsm. com/anh/en_US/feedtalks/feedtalks/eggyolk-pigmentation-guidelines.html, accessed on September 2021).

Zeaxanthin is produced by chemical synthesis, extracted from plants, or produced by microorganisms [84]. Natural zeaxanthin is mainly obtained from marigold flowers. Hence, Kemin commercializes it under the trademark ZeaONE ${ }^{\circledR}$, and DSM Nutritional Products distributes ZeaONE ${ }^{\circledR}$ under the trademark of OPTISHARP Natural. Zeaxanthin can be sold as a powder or as an oily fluid suspension at different concentrations, pure or in combination with lutein.

\section{Biotechnological Production of Carotenoids}

At present, the growing market of carotenoids is mainly met through chemical synthesis, although this has several disadvantages. First, higher production costs make chemical processes unprofitable in some cases, such as lutein or lycopene. Additionally, the chemical synthesis of carotenoids requires a very high level of control and can generate by-products that have undesirable side effects, and could cause food safety problems. Finally, these processes will become unsustainable in the near future, since they use non-renewable resources (generally from petrochemical origins, as in the case of canthaxanthin). Therefore, in light of the global economic value of carotenoids and the growing awareness of consumers, the production of carotenoids from natural or renewable sources has become an area of intense research [85].

The carotenoid biosynthetic pathway is especially amenable to manipulation by recombinant DNA techniques, since all carotenoids share two isoprene isomers as common precursors: isopentenyl diphosphate (IPP) and dimethylallyl diphosphate (DMAPP) [86,87]. Thus, the genetic modification of well-known model microorganisms has become an alternative that is growing in interest, and numerous studies are focused on the heterologous expression of important carotenoid biosynthetic genes [88-91]. As a result, the production of carotenoids from natural sources is based on the use of: (i) bacteria such as E. coli, Dietzia natronolimnaea, P. carotinifaciens or Pseudomonas putida; (ii) yeasts like X. dendrorhous, 
Yarrowia lipolytica, Saccharomyces cerevisiae or Pichia pastoris; (iii) filamentous fungi such as B. trispora; and (iv) algae such as Chlorella zofingiensis, D. salina, and Coelastrella striolata.

\subsection{Astaxanthin}

Astaxanthin is a xanthophyll carotenoid which can be found in numerous natural sources from algae and yeasts, to animals such as salmon, trout, krill, shrimp, and crayfish [92]. However, like most carotenoids, commercial astaxanthin is mainly produced by chemical synthesis (ca. 95\%), which is an expensive and unsustainable process, and natural sources such as fermentative production or crustacean byproducts are gaining importance $[3,93]$. Four natural sources are a realistic alternative to synthetic astaxanthin: (i) bacteria such as P. carotinifaciens or modified E. coli [91]; (ii) yeasts like X. dendrorhous (P. rhodozyma) or modified S. cerevisiae [94,95]; (iii) fungus such as Y. lipolytica [96]; and (iv) algae like H. pluvialis, C. zofingiensis or C. striolata [97-99].

Among natural sources, the well-known green microalgae $H$. pluvialis is the most used to date. H. pluvialis can accumulate up to 5\% DW (dry weight) of astaxanthin and, currently, is considered as the best natural source of this carotenoid. Nevertheless, it is only responsible for about $1 \%$ of the commercialized astaxanthin, despite synthetic astaxanthin having 20 times less antioxidant capacity than its natural counterpart. Thus, several important commercial companies, such as Cyanotech Corporation, Mera Pharmaceuticals Inc., AIgatechnologies or Fuji Chemical Industry Co. Ltd. are involved in large scale production of astaxanthin from $\mathrm{H}$. pluvialis [92,100].

Nonetheless, natural astaxanthin is not able to compete with the synthetic alternative at lower value-added markets currently, mainly due to the production costs (in the best case scenario, $1536 € / \mathrm{kg}$ vs. $880 € / \mathrm{kg}$, respectively) [101]. However, due to the increasing demand for natural astaxanthin and its high price, there is constant growth of astaxanthin production from natural sources over the last few years. Thus, the improvement of astaxanthin titer by microbial fermentation is required to be competitive against its synthetic manufacturing $[101,102]$. However, astaxanthin production by natural microalgae requires large open areas and long production times. This has led to numerous studies in recent years about improvement of the culture conditions, or even the genetic modifications of bacteria and yeasts for the production of astaxanthin, such as E. coli and S. cerevisiae.

A promising natural source of astaxanthin at the industrial scale is the heterobasidiomycetous yeast $X$. dendrorhous, due to its ability to accumulate large amounts of this carotenoid pigment, with productivities of $350 \mathrm{mg} / \mathrm{L}$ astaxanthin in $800 \mathrm{~L}$ fermenters [94]. Diverse studies on astaxanthin production yields by optimization of fermentation conditions revealed that its production is mainly influenced by the $\mathrm{pH}$, carbon source, nitrogen concentration and $\mathrm{Cu}^{2+}$, along with the addition of micronutrients like vitamins, trace elements, or fungal elicitors [103]. Other studies have focused on increasing astaxanthin production through genetic engineering, and the oleaginous yeast $Y$. lipolytica is a clear example. The expression of the H. pluvialis $\beta$-ketolase and $\beta$-hydroxylase genes in $Y$. lipolytica resulted in $285 \mathrm{mg} / \mathrm{L}$ astaxanthin production in $1 \mathrm{~L}$ bioreactors [96].

Far and away, the most promising strain is the well-known biotechnological chassis E. coli. This bacterium, which cannot naturally synthesize carotenoids, was genetically engineered by the introduction of carotenogenic genes. Therefore, recent studies show that the heterologous expression of $\beta$-carotene ketolase ( $\mathrm{CrtW})$ from Brevundimonas $\mathrm{sp}$. and $\beta$-carotene hydroxylase (CrtZ) from Pantoea agglomerans, along with the genetic modification of the groES and groEL chaperones, allows a production of $1.18 \mathrm{~g} / \mathrm{L}$ of astaxanthin after $60 \mathrm{~h}$ of fermentation in shake flasks (Table 1) [91].

\section{2. $\beta$-Carotene}

Although the oldest way to obtain carotenoids is extraction by physicochemical processes from plant material (the richest sources of $\beta$-carotene are dehydrated peppers, carrots and grape leaves), chemical synthesis from $\beta$-ionone has been the primary source of $\beta$-carotene production since it was developed in 1950 by Milas [104]. Nevertheless, 
among all the known methods of $\beta$-carotene production, again, microbial biosynthesis is gaining major interest. Natural $\beta$-carotene can be obtained from microalgae (D. salina), vegetables (like carrots or pumpkins), or by fermentation of microorganisms (mainly fungus as B. trispora and yeasts such as X. dendrorhous or Y. lipolytica) $[28,105,106]$.

Currently, as with astaxanthin, the main natural source of $\beta$-carotene are algae, whose production account for about $35 \%$ of total revenue. Much attention is drawn to the green microalgae D. salina, which is the main commercial source of microbial origin $[28,107]$. However, other well-known microalgae, such as C. zofingiensis, are gaining interest, and recent studies have reported that a mutant of the algae $C$. zofingiensis is able to accumulate high amounts of $\beta$-carotene ( $34.6 \mathrm{mg} / \mathrm{L}$ ) when it is induced by glucose with high light irradiation [108].

Other of the main sources of production of $\beta$-carotene is the fungus B. trispora. $\beta$-carotene production by $B$. trispora was reported in 1963 , but this achievement was abandoned because the profitability of the process was not competitive with chemical biosynthesis. However, after some decades, microbial synthesis of carotenoids has attracted researcher's attention, and great efforts have been dedicated to optimizing culture and growth conditions aimed to improve $\beta$-carotene biosynthesis from B. trispora, reaching a production of $78.0 \mathrm{mg} / \mathrm{g}$ DCW at lab scales in $2012[109,110]$. B. trispora produces $\beta$-carotene through a complex process, where mycelia of the $(+)$ and $(-)$ sexual mating types of this fungi need to be co-cultivated [111,112].

Conversely, because yeasts are unicellular organisms with a relatively high growth rate in low-cost fermentation media, they have an advantage over algae and fungi [87]. Thus, it has been reported that there is an even more promising source of natural $\beta$-carotene: the yeast $Y$. lipolytica. Despite it being best known for the industrial production of astaxanthin, it was reported that engineered Y. lipolytica strains can produce $797.1 \mathrm{mg} / \mathrm{L} \beta$-carotene as an astaxanthin intermediary. Thus, the expression of phytoene desaturase ( $c r t I)$ and lycopene cyclase $(\operatorname{crt} Y B)$ obtained from $X$. dendrorhous, along with the up-regulation of geranyl-geranyl diphosphate synthase (GGS1/crtE) and 3-hydroxy-3-methylglutaryl-CoA reductase (HMG1) and the down-regulation of the competing enzyme squalene synthase (SQS1), could increase the $\beta$-carotene biosynthesis in Y. lipolytica (Table 1) [93].

\subsection{Canthaxanthin}

Canthaxanthin was initially extracted from an edible mushroom (C. cinnabarinus) in 1950 [61], and, since then, it has been detected in several organisms as plants, trout, birds (flamingo), crayfish, fungi (A. carbonarius), algae (C. striolata, Chlorella vulgaris, C.zofingiensis, and Dictyococcus cinnabarinus), and bacteria (Bradyrhizobium sp., Dietzia sp., Gordonia jacobaea, Micrococcus roseus, Brevibacterium sp., and Rhodococcus maris) $[37,113]$. However, the development of synthetic production processes left behind natural sources of canthaxanthin for industrial production. Nowadays, some microbial sources, especially green microalgae such as $\mathrm{H}$. pluvialis and Chlorococcum sp., have gained added significance.

The search continues for microbial sources of canthaxanthin and the optimum conditions for its production. Recently, it has been reported that the overexpression of the $\beta$-carotene ketolase gene $(\mathrm{crtW})$ from Nostoc flagelliform increases canthaxanthin biosynthesis. Similar results have been observed after the heterologous expression of the $\mathrm{crtW}$ gene from Anabena variabilis in E. coli strains or from marine bacterium Paracoccus sp. In M. circinelloides [37].

Since canthaxanthin is the precursor of other carotenoids, such as astaxanthin, just a few papers have reported canthaxanthin production as the main goal (Table 1).

\subsection{Lutein}

The xanthophyll lutein generally appears in nature, along with its stereoisomer zeaxanthin, and it occurs in abundance in green leafy vegetables such as kale, collard, and spinach. Other important natural sources of lutein and zeaxanthin are egg yolk, chicken (broilers), and cheese [71,114]. 
Lutein is one of the unique carotenoids that is obtained mainly from natural sources, since its commercial production through chemical synthesis has not been viable due to its poor overall yield [115]. Currently, the flower petals of yellow Marigold (T. erecta L.) is the main source in the industrial extraction of lutein. However, marigold presents several drawbacks: (i) the flowers must be periodically harvested, and the petals have to be separated prior to extraction; (ii) lutein content in marigold petals is variable; and (iii) slow growth and low yield of biomass production [114]. Thus, there is a huge opportunity for natural lutein production from microalgae, which could become the best alternative source. Lutein biosynthesis has been reported within members of Chlorophyta (such as Scenedesmus obliquus, Chlorella minutissima, D. salina, H. pluvialis, and C. vulgaris), Chlorarachniophyta, Cryptophyta, Euglenophyta, and Rhodophyta algal species [113,115]. Two main factors make microalga a good lutein source: (i) its lutein content; and (ii) its biomass productivity. Nowadays, only Chlorella sorokiniana, Murielopsis sp., and Scenedesmus almeriensis are considered for mass production in largescale systems $[114,116]$.

One of the greatest promises in the future production of lutein is the microalgae Chlamydomonas reinhardtii, which is used as host for the heterologous expression of some carotenoid biosynthesis genes. Thus, the expression of the phytoene synthase gene (psy) from $D$. salina results in the production of 2.6-fold greater amounts of lutein compared to the wild type strain. Similar results were reported due to the overexpression of the phytoene desaturase ( $p d s)$ [117] or the expression of the phytoene- $\beta$-carotene synthase gene (pbs) from the red yeast $X$. dendrorhous, increasing, in this case, the lutein production by $60 \%$ under low light conditions $[115,118]$.

Another strategy to achieve better yields in lutein production in microalgae is the fine-tuning of culture conditions (mainly light intensity, $\mathrm{CO}_{2}$ content, color and time of exposure, temperature, and nitrogen source) of the well-known producer organisms $[119,120]$. Furthermore, 11-fold higher lutein productivity $\left(4.96 \mathrm{mg} \mathrm{L}^{-1} \mathrm{~d}^{-1}\right)$ has been reported in

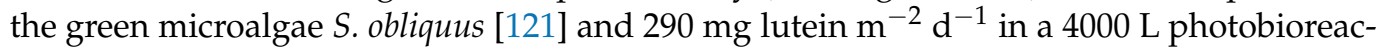
tor for S. almeriensis [122]. Similarly, growth and lutein production processes have been optimized for the algae Chlorella sorokiniana and Chlorella protothecoides, although all these assays are still being carried out at the bench or pilot scales (Table 1) [115].

Finally, lutein producing bacteria has yet been found in nature, however the genetic modification of the cyanobacteria Synechocystis sp. PCC to express $\beta$-and $\varepsilon$-cyclase, and $\beta$-and $\varepsilon$-hydroxylase from Arabidopsis, results in a lutein producing strain [34].

\subsection{Lycopene}

Lycopene is naturally present in fruits and vegetables such as papayas, red peppers and, especially, tomatoes (about $80 \%$ of their total carotenoid content) [86,123], which is one of the main sources of lycopene nowadays [124]. However, increasing demand for lycopene has led to a search for new sources. Thus, although lycopene can be synthesized chemically, its production process is extremely complex and costly, highlighting microbial synthesis as a promising method in recent years [86].

As in most cases, the model microorganism E. coli was one of the first developed chassis for lycopene production, reaching titers of $2.7 \mathrm{~g} / \mathrm{L}$. Nevertheless, the release of some endotoxins during the fermentation process has led other microorganisms, especially well-known industrial yeasts such as S. cerevisiae, P. pastoris or Y. lipolytica, to take the lead in the development of new lycopene production processes. The production of lycopene by the fungus $B$. trispora was previously reported, but numerous studies have focused on the use of yeast because $B$. trispora requires the addition of cyclase inhibitors such as imidazole or pyridine derivatives, in order to avoid formation of $\beta$-carotene. Besides, yeasts usually possess endogenous carotenoid metabolic pathways, so they can easily be genetically modified to drive metabolic flux toward lycopene synthesis from the common precursors isopentyl diphosphate (IPP) and dimethyl diphosphate (DMAPP).

Some species are able to produce natural lycopene, such as X. denrorhous (P. rhodozyma). However, due to the lack of genetic manipulation tools, the product concentration by using 
this natural yeast is not usually high, and they are not reported as industrial producers. Thus, they just provide gene elements occurring in lycopene heterologous synthesis pathways [86]. Three key crt genes are necessary for a heterologous lycopene pathway expression: (i) $c r t E$, GGPP synthase, catalyzes the first step of downstream lycopene biosynthesis; (ii) $\operatorname{crtB}$, phytoene synthase, leads to the formation of the colorless phytoene; and (iii) crtI, phytoene desaturase, catalyzes the conversion of phytoene to lycopene. Thus, the heterologous expression of two copies of $\mathrm{crtE}$ from Pantoea ananatis, two copies of $\mathrm{crtI}$ from B. trispora, and one copy of crtB from P. agglomerans in S. cerevisiae, along with the knocking out of endogenous bypass genes, culminates in the production of $3.28 \mathrm{~g} / \mathrm{L}$ lycopene in 7-L fermenters [125] (Table 1).

Finally, through a combination of the modification of the native isopentenol utilization pathway (IUP) in the oleaginous yeast $Y$. lipolytica, with further genetic and fermentation optimizations, a final lycopene titer of $4.2 \mathrm{~g} / \mathrm{L}$ was achieved in 3-L bioreactors [126] (Table 1).

\subsection{Zeaxanthin}

To date, the xanthophyll zeaxanthin has been mainly produced by extraction from natural sources like green vegetables and yellow corn, although it can also be found in oranges, tangerines, spinach, lettuce, squash, and chicken egg yolk. Zeaxanthin could be chemically synthesized, but the process is complex and expensive. Therefore, natural alternatives lead the sources of industrial production, even when the processes net low extraction rates and produce large amounts of waste. As a result, the idea of using new biological technology has attracted more and more attention in the last years, although, so far, all these studies continue on a bench scale. Compared with other carotenoids, zeaxanthin production rates are extremely low and the use of metabolically engineered microorganisms as a source is sought.

Many bacteria are able to naturally accumulate zeaxanthin; the best-known among them are those of the genera Mesoflavibacter and Muricauda. For example, it has been reported that Muricauda lutaonensis is able to produce $3.12 \mathrm{mg} \mathrm{L}^{-1}$ of zeaxanthin when cultured in 2-L biorreactors [127], and Mesoflavibacter zeaxanthinifaciens showed a production yield of $910 \mu \mathrm{g} / \mathrm{g}$ DCW at the lab scale (Table 1) [128].

To date, there are two realistic industrial sources of zeaxanthin: bacteria and algae. By far the most promising algae is $C$. zofingiensis, which after random mutagenesis with $\mathrm{N}$-methyl-N'-nitro-N-nitrosoguanidine (MNNG), was able to accumulate $36.79 \mathrm{mg} / \mathrm{L}$ zeaxanthin when induced by glucose and growing with nitrogen deficiency and high light irradiation; an especially remarkable fact since no algae have been found to have profitable potential for zeaxanthin production [108]. On the other hand, gene editing using CRISPR-Cas9 was conducted in C. reinhardtii aimed to eliminate the synthesis of lutein and enhance the production of high purity zeaxanthin, resulting in a mutant able to produce $6.84 \mathrm{mg} / \mathrm{L}$ zeaxanthin [129].

Finally, among the most promising bacteria it is worth highlighting the model host E. coli. Thus, it has been reported that the heterologous expression of the $\operatorname{ctr} Y$ and $\operatorname{ctr} Z$ genes from P. ananatis resulted in the production of $11.95 \mathrm{mg} / \mathrm{g}$ DCW of zeaxanthin [89], levels much higher than those discussed initially. Unfortunately, these levels do not reach those shown by the well-known P. putida, which produces $51.3 \mathrm{mg} / \mathrm{L}$ of zeaxanthin after expression of the $\mathrm{crt}$ genes from P. ananatis and optimization of the fermentation parameters (Table 1) [130]. 
Table 1. Summary of carotenoids production from different microbial sources based on data provided by authors.

\begin{tabular}{|c|c|c|c|}
\hline Carotenoid & Strain & Titer/Yield & Reference \\
\hline \multirow{7}{*}{ 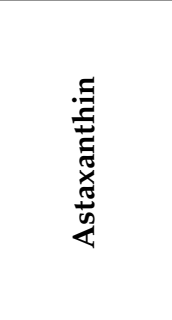 } & $\begin{array}{c}\text { Xanthophyllomyces dendrorhous } \\
\text { (Phaffia rhodozyma) }\end{array}$ & $350.0 \mathrm{mg} / \mathrm{L}(4.1 \mathrm{mg} / \mathrm{g} \mathrm{DCW})$ & [94] \\
\hline & Yarrowia lipolytica & $285.0 \mathrm{mg} / \mathrm{L}(6 \mathrm{mg} / \mathrm{g}$ DCW $)$ & [96] \\
\hline & Saccharomyces cerevisiae & $47.0 \mathrm{mg} / \mathrm{L}(8 \mathrm{mg} / \mathrm{g} \mathrm{DCW})$ & [95] \\
\hline & Haematococcus pluvialis & $29.3 \mathrm{mg} / \mathrm{g}$ DCW & [97] \\
\hline & Chlorella zofingiensis & $3.9 \mathrm{mg} / \mathrm{g}$ DCW & [98] \\
\hline & Coelastrella striolata & $1.5 \mathrm{mg} / \mathrm{g} \mathrm{DCW}$ & [99] \\
\hline & Escherichia coli & $6.17 \mathrm{mg} / \mathrm{g}$ DCW & [91] \\
\hline \multirow{8}{*}{ 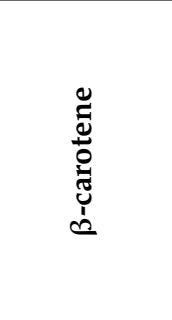 } & Yarrowia lipolytica & $90 \mathrm{mg} / \mathrm{g} \mathrm{DCW}$ & [131] \\
\hline & Blakeslea trispora & $78.0 \mathrm{mg} / \mathrm{g} \mathrm{DCW}$ & [110] \\
\hline & Sporobolomyces roseus & $2.6 \mathrm{mg} / \mathrm{g}$ DCW & [132] \\
\hline & Rhodotorula glutinis & $1.3 \mathrm{mg} / \mathrm{g} \mathrm{DCW}$ & [132] \\
\hline & Saccharomyces cerevisiae & $5.9 \mathrm{mg} / \mathrm{g} \mathrm{DCW}$ & [133] \\
\hline & Dunaliella salina & $25.2 \mathrm{mg} / \mathrm{g} \mathrm{DCW}$ & [134] \\
\hline & Coelastrella striolata & $7.0 \mathrm{mg} / \mathrm{g}$ DCW & [99] \\
\hline & Chlorella zofingiensis & $7.2 \mathrm{mg} / \mathrm{g}$ DCW & {$[108]$} \\
\hline \multirow{6}{*}{ 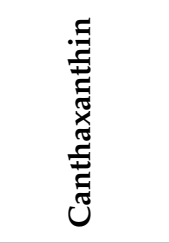 } & Aspergillus carbonarius & $206.0 \mathrm{mg} / \mathrm{g}$ DCW & [63] \\
\hline & Chlorella zofingiensis & $0.26 \mathrm{mg} / \mathrm{g}$ DCW & [135] \\
\hline & Dietzia natronolimnaea & $0.9 \mathrm{mg} / \mathrm{g}$ DCW & [136] \\
\hline & Rhodococcus maris & $13.4 \mu \mathrm{g} / \mathrm{g} \mathrm{DCW}$ & [137] \\
\hline & Coelastrella striolata & $47.5 \mathrm{mg} / \mathrm{g} \mathrm{DCW}$ & [99] \\
\hline & Escherichia coli & $10.6 \mathrm{mg} / \mathrm{g}$ DCW & [90] \\
\hline \multirow{6}{*}{ 急 } & Scenedesmus bijugus & $2.9 \mathrm{mg} / \mathrm{g} \mathrm{DCW}$ & \\
\hline & Chlorella sorokiniana & $5.9 \mathrm{mg} / \mathrm{g} \mathrm{DCW}$ & \\
\hline & Chlorella sp. & $2.3 \mathrm{mg} / \mathrm{g} \mathrm{DCW}$ & [138] \\
\hline & Coelastrella sp. & $6.5 \mathrm{mg} / \mathrm{g}$ DCW & \\
\hline & Vischeria stellata & $1.5 \mathrm{mg} / \mathrm{g}$ DCW & \\
\hline & Chlorella zofingiensis & $13.8 \mathrm{mg} / \mathrm{g}$ DCW & [108] \\
\hline \multirow{7}{*}{ 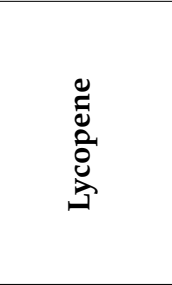 } & Blakeslea trispora & $24.0 \mathrm{mg} / \mathrm{g} \mathrm{DCW}$ & [139] \\
\hline & Rhodotorula glutinis & $340.0 \mathrm{mg} / \mathrm{L}$ & [140] \\
\hline & Yarrowia lipolytica & $21.1 \mathrm{mg} / \mathrm{g} \mathrm{DCW}$ & [141] \\
\hline & Dietzia natronolimnaea & $0.9 \mathrm{mg} / \mathrm{g} \mathrm{DCW}$ & [142] \\
\hline & Dunaliella salina & $0.7 \mathrm{mg} / \mathrm{L}$ & [143] \\
\hline & Saccharomyces cerevisiae & $3.3 \mathrm{~g} / \mathrm{L}$ & [125] \\
\hline & Pichia pastoris & $9.3 \mathrm{mg} / \mathrm{g} \mathrm{DCW}$ & [144] \\
\hline \multirow{12}{*}{ 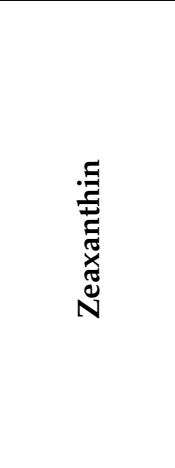 } & Mucor circinelloides & $10.0 \mu \mathrm{g} / \mathrm{g} \mathrm{DCW}$ & [145] \\
\hline & Mesoflavibacter zeaxanthinifaciens & $0.9 \mathrm{mg} / \mathrm{g} \mathrm{DCW}$ & [146] \\
\hline & Muricauda lutaonensis & $2.7 \mathrm{mg} / \mathrm{g} \mathrm{DCW}$ & [127] \\
\hline & Siansivirga zeaxanthinifaciens & $6.5 \mathrm{mg} / \mathrm{g} \mathrm{DCW}$ & [147] \\
\hline & Sphingomonas natatoria & $4.9 \mathrm{mg} / \mathrm{g} \mathrm{DCW}$ & [148] \\
\hline & Escherichia coli & $12.0 \mathrm{mg} / \mathrm{g} \mathrm{DCW}$ & [89] \\
\hline & Algibacter sp. & $11.4 \mathrm{mg} / \mathrm{g} \mathrm{DCW}$ & [149] \\
\hline & Paracoccus zeaxanthinifaciens & $1.3 \mathrm{mg} / \mathrm{g} \mathrm{DCW}$ & [150] \\
\hline & Pseudomonas putida & $7.0 \mathrm{mg} / \mathrm{g} \mathrm{DCW}$ & [130] \\
\hline & Chlorella zofingiensis & $7.0 \mathrm{mg} / \mathrm{g}$ DCW & [108] \\
\hline & Arthorbacter gardavensis & $1.5 \mathrm{mg} / \mathrm{g} \mathrm{DCW}$ & [151] \\
\hline & Chlamydomonas reinhardtii & $7.3 \mathrm{mg} / \mathrm{g} \mathrm{DCW}$ & [129] \\
\hline
\end{tabular}

\section{Future Outlook}

Currently, the entirety of the carotenoids market is dominated by chemical synthesis, but natural carotenoids obtained from plants, animals, and microorganisms, due to their higher biological and health properties, are taking the attention of those markets that demand natural products. The microbiological production of these industrially-relevant compounds appears to be a suitable alternative, which still needs future development on strain selection, omics methodology applications as data sources for synthetic biology 
developments, and culture condition improvements. However, consumer priorities are driving the transition from chemical to biological production, where fungi, bacteria, and algae are the main players.

The nutritional (food and feed), health, and cosmetics applications of these colored compounds have profitable benefits today, which will be increased due to food and beverage supplementation, intensive aquiculture as substitute for fishery depletion, and health properties.

Carotenoid discovery, research and development has a long story, which is as highly active and industrially attractive now more than ever.

Author Contributions: Conceptualization and writing-original draft preparation, C.B. and J.-L.B.; writing-review and editing S.M.-C., S.R. and A.I. All authors have read and agreed to the published version of the manuscript.

Funding: This research received no external funding.

Acknowledgments: Authors wish to thank: (i) the ProWood project ("Wood and derivatives protection by novel bio-coating solutions", ERA IB 7th Joint Call) through the APCIN call of the Spanish Ministry of Economy and Competitiveness (MINECO, Spain) (Project ID: PCIN-2016-081); and (ii) the Syntheroids project (Synthetic biology for industrial production of steroids; ERA CoBioTech 1st call) through the APCIN call of the Spanish Ministry of Science, Innovation and Universities (Project ID: PCI2018-093066) and through the CDTI call (EXP-00108753/SERA-20181033). The authors also wish to thank the English style review by Joe DeAngelo, as well as the staff involved, over recent decades, in the secondary metabolism and carotenoids research teams of the University of León (Spain), INBIOTEC and Curia.

Conflicts of Interest: The authors declare no conflict of interest.

Entry Link on the Encyclopedia Platform: https:/ /encyclopedia.pub/17342.

\section{References}

1. Saini, R.K.; Keum, Y.S. Progress in Microbial Carotenoids Production. Indian J. Microbiol. 2017, 57, 129-130. [CrossRef] [PubMed]

2. Pfander, H.; Lanz, M.; Traber, B. Synthesis of carotenoids. In Studies in Natural Products Chemistry; Rahman, A., Ed.; Elsevier Science: Amsterdam, The Netherlands, 1997; Volume 20, pp. 561-612.

3. Barreiro, C.; Barredo, J. (Eds.) Carotenoids production: A healthy and profitable industry. In Microbial Carotenoids: Methods and Protocols; Springer Science+Business Media: New York, NY, USA, 2018; pp. 45-55. ISBN 9781493987429.

4. Langi, P.; Kiokias, S.; Varzakas, T.; Proestos, C. Carotenoids: From plants to food and feed industries. In Microbial Carotenoids: Methods and Protocols; Barreiro, C., Barredo, J., Eds.; Springer Science: Amsterdam, The Netherlands, 2018 ; pp. 57-71.

5. Bhosale, P.; Bernstein, P.S. Microbial xanthophylls. Appl. Microbiol. Biotechnol. 2005, 68, 445-455. [CrossRef]

6. Yabuzaki, J. Carotenoids Database: Structures, chemical fingerprints and distribution among organisms. Database 2017, 2017, bax004. [CrossRef]

7. Fernandes, A.S.; Do Nascimento, T.C.; Jacob-Lopes, E.; De Rosso, V.V.; Zepka, L.Q. Carotenoids-A brief overview on its structure, biosynthesis, synthesis, and applications. Prog. Carotenoid Res. 2018, 1-16. [CrossRef]

8. Barredo, J.; García-Estrada, C.; Kosalkova, K.; Barreiro, C. Biosynthesis of astaxanthin as a main carotenoid in the eterobasidiomycetous yeast Xanthophyllomyces dendrorhous. J. Fungi 2017, 3, 44. [CrossRef] [PubMed]

9. Gómez-García, M.R.; Ochoa-Alejo, N. Biochemistry and molecular biology of carotenoid biosynthesis in chili peppers (Capsicum spp.). Int. J. Mol. Sci. 2013, 14, 19025-19053. [CrossRef]

10. Moran, N.A.; Jarvik, T. Lateral transfer of genes from fungi underlies carotenoid production in aphids. Science 2010, 328, 624-627. [CrossRef]

11. Barreiro, C.; Gutiérrez, S.; Olivera, E.R. Fungal Horizontal Gene Transfer: A History Beyond the Phylogenetic Kingdoms. In Horizontal Gene Transfer; Villa, T., Viñas, M., Eds.; Springer International Publishing: Cham, Switzerland, 2019; pp. 315-336. ISBN 9783030218621.

12. Klassen, J.L. Phylogenetic and evolutionary patterns in microbial carotenoid biosynthesis are revealed by comparative genomics. PLoS ONE 2010, 5, e11257. [CrossRef]

13. Hammond, B.R.; Renzi, L.M. Carotenoids. Adv. Nutr. 2013, 4, 474-476. [CrossRef] [PubMed]

14. Isler, O. Introduction. In Carotenoids; Isler, O., Gutmann, H., Ulrich, S., Eds.; Springer Basel AG: Basel, Switzerland, 1971 ; pp. 12-25. ISBN 978-3-0348-5832-8.

15. Isler, O. History and Industrial Application of Carotenoids and Vitamin A (1). Pure Appl. Chem. 1979, 51, 447-462. [CrossRef]

16. José Bagur, M.; Alonso Salinas, G.; Jiménez-Monreal, A.; Chaouqi, S.; Llorens, S.; Martínez-Tomé, M.; Alonso, G. Saffron: An old medicinal plant and a potential novel functional food. Molecules 2017, 23, 30. [CrossRef] [PubMed] 
17. Walter, M.H.; Strack, D. Carotenoids and their cleavage products: Biosynthesis and functions. Nat. Prod. Rep. 2011, $28,663-692$. [CrossRef]

18. Pandita, D. Saffron (Crocus sativus L.): Phytochemistry, therapeutic significance and omics-based biology. In Medicinal and Aromatic Plants; Elsevier: Amsterdam, The Netherlands, 2021; pp. 325-396. ISBN 978-0-12-819590-1.

19. Singla, R.K.; Bhat, V.G. Crocin: An overview. Indo Glob. J. Pharm. Sci. 2014, 1, 281-286.

20. Sourkes, T.L. The discovery and early history of carotene. Bull. Hist. Chem. 2009, 34, 33.

21. Vogele, A.C. Effect of environmental factors upon the color of the tomato and the watermelon. Plant Physiol. 1937, 12, 929-955. [CrossRef]

22. Meroni, E.; Raikos, V. Lycopene in beverage emulsions: Optimizing formulation design and processing effects for enhanced delivery. Beverages 2018, 4, 14. [CrossRef]

23. The xanthophyll group of yellow colouring matters. Proc. R. Soc. Lond. 1904, 72, 165-176. [CrossRef]

24. Willstätter, R.; Mieg, W. Untersuchungen über Chlorophyll; IV. Ueber die gelben Begleiter des Chlorophylls. Justus Liebig's Ann. Chem. 1907, 355, 1-28. [CrossRef]

25. Buttriss, J.L.; Welch, A.A.; Kearney, J.M.; Lanham-New, S.A. (Eds.) Public Health Nutrition, 2nd ed.; Wiley-Blackwell: Hoboken, FJ, USA, 2017; ISBN 978-1-118-66097-3.

26. Isler, O.; Huber, W.; Ronco, A.; Kofler, M. Synthese des Vitamin A. Helv. Chim. Acta 1947, 30, 1911-1927. [CrossRef] [PubMed]

27. Ernst, H. Recent advances in industrial carotenoid synthesis. Pure Appl. Chem. 2002, 74, 2213-2226. [CrossRef]

28. Bogacz-Radomska, L.; Harasym, J. $\beta$-Carotene-Properties and production methods. Food Qual. Saf. 2018, 2, 69-74. [CrossRef]

29. Khachik, F. Distribution and metabolism of dietary carotenoids in humans as a criterion for development of nutritional supplements. Pure Appl. Chem. 2006, 78, 1551-1557. [CrossRef]

30. Demain, A.L.; Sánchez, S. Advancement of biotechnology by genetic modifications. In Microbial Carotenoids: Methods and Protocols; Barreiro, C., Barredo, J.L., Eds.; Springer Nature: New York, NY, USA, 2018; Volume 1852, pp. 1-43. ISBN 9781493987429.

31. Xue, D.; Abdallah, I.I.; de Haan, I.E.M.; Sibbald, M.J.J.B.; Quax, W.J. Enhanced C30 carotenoid production in Bacillus subtilis by systematic overexpression of MEP pathway genes. Appl. Microbiol. Biotechnol. 2015, 99, 5907-5915. [CrossRef] [PubMed]

32. Furubayashi, M.; Ikezumi, M.; Takaichi, S.; Maoka, T.; Hemmi, H.; Ogawa, T.; Saito, K.; Tobias, A.V.; Umeno, D. A highly selective biosynthetic pathway to non-natural C50 carotenoids assembled from moderately selective enzymes. Nat. Commun. 2015, 6, 7534. [CrossRef]

33. Gong, G.; Liu, L.; Zhang, X.; Tan, T. Multi-omics metabolism analysis on irradiation-induced oxidative stress to Rhodotorula glutinis. Appl. Microbiol. Biotechnol. 2019, 103, 361-374. [CrossRef]

34. Lehmann, M.; Vamvaka, E.; Torrado, A.; Jahns, P.; Dann, M.; Rosenhammer, L.; Aziba, A.; Leister, D.; Rühle, T. Introduction of the carotenoid biosynthesis $\alpha$-branch into Synechocystis sp. PCC 6803 for lutein production. Front. Plant Sci. 2021, 12. [CrossRef] [PubMed]

35. Visser, H.; van Ooyen, A.J.J.; Verdoes, J.C. Metabolic engineering of the astaxanthin-biosynthetic pathway of Xanthophyllomyces dendrorhous. FEMS Yeast Res. 2003, 4, 221-231. [CrossRef]

36. Wang, E.; Dong, C.; Zhang, P.; Roberts, T.H.; Park, R.F. Carotenoid biosynthesis and the evolution of carotenogenesis genes in rust fungi. Fungal Biol. 2021, 125, 400-411. [CrossRef]

37. Rebelo, B.A.; Farrona, S.; Ventura, M.R.; Abranches, R. Canthaxanthin, a red-hot carotenoid: Applications, synthesis, and biosynthetic evolution. Plants 2020, 9, 1039. [CrossRef]

38. Misawa, N.; Kajiwara, S.; Kondo, K.; Yokoyama, A.; Satomi, Y.; Saito, T.; Miki, W.; Ohtani, T. Canthaxanthin biosynthesis by the conversion of methylene to keto groups in a hydrocarbon $\beta$-carotene by a single gene. Biochem. Biophys. Res. Commun. 1995, 209, 867-876. [CrossRef]

39. Rodríguez-Sáiz, M.; de la Fuente, J.L.; Barredo, J.L. Xanthophyllomyces dendrorhous for the industrial production of astaxanthin. Appl. Microbiol. Biotechnol. 2010, 88, 645-658. [CrossRef] [PubMed]

40. Misawa, N.; Satomi, Y.; Kondo, K.; Yokoyama, A.; Kajiwara, S.; Saito, T.; Ohtani, T.; Miki, W. Structure and functional analysis of a marine bacterial carotenoid biosynthesis gene cluster and astaxanthin biosynthetic pathway proposed at the gene level. $J$. Bacteriol. 1995, 177, 6575-6584. [CrossRef] [PubMed]

41. Ambati, R.R.; Gogisetty, D.; Aswathanarayana, R.G.; Ravi, S.; Bikkina, P.N.; Bo, L.; Yuepeng, S. Industrial potential of carotenoid pigments from microalgae: Current trends and future prospects. Crit. Rev. Food Sci. Nutr. 2019, 59, 1880-1902. [CrossRef]

42. Novoveská, L.; Ross, M.E.; Stanley, M.S.; Pradelles, R.; Wasiolek, V.; Sassi, J.F. Microalgal carotenoids: A review of production, current markets, regulations, and future direction. Mar. Drugs 2019, 17, 640. [CrossRef] [PubMed]

43. Vílchez, C.; Forján, E.; Cuaresma, M.; Bédmar, F.; Garbayo, I.; Vega, J.M. Marine carotenoids: Biological functions and commercial applications. Mar. Drugs 2011, 9, 319-333. [CrossRef] [PubMed]

44. Ram, S.; Mitra, M.; Shah, F.; Tirkey, S.R.; Mishra, S. Bacteria as an alternate biofactory for carotenoid production: A review of its applications, opportunities and challenges. J. Funct. Foods 2020, 67, 103867. [CrossRef]

45. Eggersdorfer, M.; Wyss, A. Carotenoids in human nutrition and health. Arch. Biochem. Biophys. 2018, 652, 18-26. [CrossRef]

46. Fiedor, J.; Burda, K. Potential role of carotenoids as antioxidants in human health and disease. Nutrients 2014, 6, 466-488. [CrossRef]

47. Sathasivam, R.; Ki, J.-S. A Review of the Biological Activities of Microalgal Carotenoids and Their Potential Use in Healthcare and Cosmetic Industries. Mar. Drugs 2018, 16, 26. [CrossRef] 
48. Granado, F.; Olmedilla, B.; Blanco, I. Nutritional and clinical relevance of lutein in human health. Br. J. Nutr. 2003, 90, 487. [CrossRef]

49. Masaki, H. Role of antioxidants in the skin: Anti-aging effects. J. Dermatol. Sci. 2010, 58, 85-90. [CrossRef] [PubMed]

50. Nabi, F.; Arain, M.A.; Rajput, N.; Alagawany, M.; Soomro, J.; Umer, M.; Soomro, F.; Wang, Z.; Ye, R.; Liu, J. Health benefits of carotenoids and potential application in poultry industry: A review. J. Anim. Physiol. Anim. Nutr. 2020, 104, 1809-1818. [CrossRef]

51. Bjerkeng, B. Carotenoids in Aquaculture: Fish and Crustaceans. In Carotenoids; Britton, G., Liaaen-Jensen, S., Pfander, H., Eds.; Birkhäuser Basel: Basel, Switzerland, 2008; Volume 4, pp. 237-254. ISBN 978-3-7643-7498-3.

52. Sztretye, M.; Dienes, B.; Gönczi, M.; Czirják, T.; Csernoch, L.; Dux, L.; Szentesi, P.; Keller-Pintér, A. Astaxanthin: A potential mitochondrial-targeted antioxidant treatment in diseases and with aging. Oxid. Med. Cell. Longev. 2019, 2019, 3849692. [CrossRef]

53. Li, X.; Wang, X.; Duan, C.; Yi, S.; Gao, Z.; Xiao, C.; Agathos, S.N.; Wang, G.; Li, J. Biotechnological production of astaxanthin from the microalga Haematococcus pluvialis. Biotechnol. Adv. 2020, 43, 107602. [CrossRef]

54. Saini, R.K.; Nile, S.H.; Park, S.W. Carotenoids from fruits and vegetables: Chemistry, analysis, occurrence, bioavailability and biological activities. Food Res. Int. 2015, 76, 735-750. [CrossRef]

55. Khoo, H.E.; Prasad, K.N.; Kong, K.W.; Jiang, Y.; Ismail, A. Carotenoids and their isomers: Color pigments in fruits and vegetables. Molecules 2011, 16, 1710-1738. [CrossRef]

56. Grune, T.; Lietz, G.; Palou, A.; Ross, A.C.; Stahl, W.; Tang, G.; Thurnham, D.; Yin, S.; Biesalski, H.K. $\beta$-Carotene is an important vitamin A source for humans. J. Nutr. 2010, 140, 2268S-2285S. [CrossRef]

57. Weber, D.; Grune, T. The contribution of $\beta$-carotene to vitamin A supply of humans. Mol. Nutr. Food Res. 2012, 56, 251-258. [CrossRef] [PubMed]

58. Jiang, Y.-W.; Sun, Z.-H.; Tong, W.-W.; Yang, K.; Guo, K.-Q.; Liu, G.; Pan, A. Dietary intake and circulating concentrations of carotenoids and risk of type 2 diabetes: A dose-response meta-analysis of prospective observational studies. Adv. Nutr. 2021, 12, 1723-1733. [CrossRef]

59. Mary, A.E.P.; Artavia Mora, J.I.; Ronda Borzone, P.A.; Richards, S.E.; Kies, A.K. Vitamin E and beta-carotene status of dairy cows: A survey of plasma levels and supplementation practices. Animal 2021, 15, 100303. [CrossRef] [PubMed]

60. LeBlanc, S.J.; Herdt, T.H.; Seymour, W.M.; Duffield, T.F.; Leslie, K.E. Peripartum serum vitamin E, retinol, and beta-carotene in dairy cattle and their associations with disease. J. Dairy Sci. 2004, 87, 609-619. [CrossRef]

61. Haxo, F. Carotenoids of the mushroom Cantharellus cinnabarinus. Bot. Gaz. 1950, 112, 228-232. [CrossRef]

62. Esatbeyoglu, T.; Rimbach, G. Canthaxanthin: From molecule to function. Mol. Nutr. Food Res. 2017, 61, 1-49. [CrossRef]

63. Krupa, D.; Nakkeeran, E.; Kumaresan, N.; Vijayalakshmi, G.; Subramanian, R. Extraction, purification and concentration of partially saturated canthaxanthin from Aspergillus carbonarius. Bioresour. Technol. 2010, 101, 7598-7604. [CrossRef] [PubMed]

64. Nasri Nasrabadi, M.R.; Razavi, S.H. Enhancement of canthaxanthin production from Dietzia natronolimnaea HS-1 in a fed-batch process using trace elements and statistical methods. Braz. J. Chem. Eng. 2010, 27, 517-529. [CrossRef]

65. Hojjati, M.; Razavi, S.H.; Rezaei, K.; Gilani, K. Stabilization of canthaxanthin produced by Dietzia natronolimnaea HS-1 with spray drying microencapsulation. J. Food Sci. Technol. 2014, 51, 2134-2140. [CrossRef] [PubMed]

66. Beaulieu, R.A.; Warwar, R.E.; Buerk, B.M. Canthaxanthin retinopathy with visual loss: A case report and review. Case Rep. Ophthalmol. Med. 2013, 2013, 1600469. [CrossRef]

67. European Food Safety Authority. Scientific Opinion on the Re-Evaluation of Canthaxanthin (E 161 g) as a Food Additive. EFSA J. 2010, 8, 1852. [CrossRef]

68. Bone, R.A.; Landrum, J.T.; Cao, Y.; Howard, A.N.; Alvarez-Calderon, F. Macular pigment response to a supplement containing meso-zeaxanthin, lutein and zeaxanthin. Nutr. Metab. 2007, 4, 12. [CrossRef]

69. Ma, L.; Yan, S.-F.; Huang, Y.-M.; Lu, X.-R.; Qian, F.; Pang, H.-L.; Xu, X.-R.; Zou, Z.-Y.; Dong, P.-C.; Xiao, X.; et al. Effect of lutein and zeaxanthin on macular pigment and visual function in patients with early age-related macular degeneration. Ophthalmology 2012, 119, 2290-2297. [CrossRef]

70. Johra, F.T.; Bepari, A.K.; Bristy, A.T.; Reza, H.M. A mechanistic review of $\beta$-carotene, lutein, and zeaxanthin in eye health and disease. Antioxidants 2020, 9, 1046. [CrossRef]

71. Nwachukwu, I.D.; Udenigwe, C.C.; Aluko, R.E. Lutein and zeaxanthin: Production technology, bioavailability, mechanisms of action, visual function, and health claim status. Trends Food Sci. Technol. 2016, 49, 74-84. [CrossRef]

72. Grether-Beck, S.; Marini, A.; Jaenicke, T.; Stahl, W.; Krutmann, J. Molecular evidence that oral supplementation with lycopene or lutein protects human skin against ultraviolet radiation: Results from a double-blinded, placebo-controlled, crossover study. Br. J. Dermatol. 2017, 176, 1231-1240. [CrossRef] [PubMed]

73. Kavalappa, Y.P.; Gopal, S.S.; Ponesakki, G. Lutein inhibits breast cancer cell growth by suppressing antioxidant and cell survival signals and induces apoptosis. J. Cell. Physiol. 2021, 236, 1798-1809. [CrossRef] [PubMed]

74. Johnson, E.J.; Mcdonald, K.; Caldarella, S.M.; Chung, H.; Troen, A.M.; Snodderly, D.M. Cognitive findings of an exploratory trial of docosahexaenoic acid and lutein supplementation in older women. Nutr. Neurosci. 2008, 11, 75-83. [CrossRef]

75. Breithaupt, D.R. Xanthophylls in Poultry Feeding. In Carotenoids: Volume 4: Natural Functions; Britton, G., Liaaen-Jensen, S., Pfander, H., Eds.; Birkhäuser Basel: Basel, Switzerland, 2008; pp. 255-264. ISBN 978-3-7643-7499-0.

76. Sirri, F.; Iaffaldano, N.; Minelli, G.; Meluzzi, A.; Rosato, M.P.; Franchini, A. Comparative pigmentation efficiency of high dietary levels of apo-ester and marigold extract on quality traits of whole liquid egg of two strains of laying hens. J. Appl. Poult. Res. 2007, 16, 429-437. [CrossRef] 
77. Hadden, W.L.; Watkins, R.H.; Levy, L.W.; Regalado, E.; Rivadeneira, D.M.; van Breemen, R.B.; Schwartz, S.J. Carotenoid composition of Marigold (Tagetes erecta) flower extract used as nutritional supplement. J. Agric. Food Chem. 1999, 47, 4189-4194. [CrossRef]

78. Authority, E.F.S. Safety of synthetic lycopene-Scientific opinion of the panel on scientific panel on dietetic products, nutrition and allergies. EFSA J. 2008, 6, 676. [CrossRef]

79. Aghajanpour, M.; Nazer, M.R.; Obeidavi, Z.; Akbari, M.; Ezati, P.; Kor, N.M. Functional foods and their role in cancer prevention and health promotion: A comprehensive review. Am. J. Cancer Res. 2017, 7, 740-769.

80. Marzocco, S.; Singla, R.K.; Capasso, A. Multifaceted effects of lycopene: A boulevard to the multitarget-based treatment for cancer. Molecules 2021, 26, 5333. [CrossRef]

81. Müller, L.; Caris-Veyrat, C.; Lowe, G.; Böhm, V. Lycopene and its antioxidant role in the prevention of cardiovascular diseases-A critical review. Crit. Rev. Food Sci. Nutr. 2016, 56, 1868-1879. [CrossRef]

82. Mozos, I.; Stoian, D.; Caraba, A.; Malainer, C.; Horbańczuk, J.O.; Atanasov, A.G. Lycopene and vascular health. Front. Pharmacol. 2018, 9, 521. [CrossRef]

83. European Food Safety Authority. Scientific Opinion on the Substantiation of Health Claims Related to Lycopene and Protection of DNA, Proteins and Lipids from Oxidative Damage (ID 1608, 1609, 1611, 1662, 1663, 1664, 1899, 1942, 2081, 2082, 2142, 2374), Protection of the Skin from UV-Indu. EFSA J. 2011, 9, 2031. [CrossRef]

84. Sajilata, M.G.; Singhal, R.S.; Kamat, M.Y. The carotenoid pigment zeaxanthin-A review. Compr. Rev. Food Sci. Food Saf. 2008, 7, 29-49. [CrossRef]

85. Khodaiyan, F.; Razavi, S.H.; Emam-Djomeh, Z.; Mousavi, S.M.A.; Hejazi, M.A. Effect of culture conditions on canthaxanthin production by Dietzia natronolimnaea HS-1. J. Microbiol. Biotechnol. 2007, 17, 195-201.

86. Jing, Y.; Guo, F.; Zhang, S.; Dong, W.; Zhou, J.; Xin, F.; Zhang, W.; Jiang, M. Recent Advances on Biological Synthesis of Lycopene by Using Industrial Yeast. Ind. Eng. Chem. Res. 2021, 60, 3485-3494. [CrossRef]

87. Sanchez, S.; Ruiz, B.; Rodríguez-Sanoja, R.; Flores-Cotera, L.B. Microbial production of carotenoids. In Microbial Production of Food Ingredients, Enzymes and Nutraceuticals; Elsevier: Amsterdam, The Netherlands, 2013; pp. 194-233. ISBN 978-0-85709-354-7.

88. Misawa, N. Carotenoids. In Comprehensive Natural Products II; Liu, H.W.B., Mander, L., Eds.; Elsevier: Amsterdam, The Netherlands, 2010; pp. 733-753. ISBN 978-0-08-045382-8.

89. Li, X.-R.; Tian, G.-Q.; Shen, H.-J.; Liu, J.-Z. Metabolic engineering of Escherichia coli to produce zeaxanthin. J. Ind. Microbiol. Biotechnol. 2015, 42, 627-636. [CrossRef] [PubMed]

90. Scaife, M.A.; Prince, C.A.; Norman, A.; Armenta, R.E. Progress toward an Escherichia coli canthaxanthin bioprocess. Process Biochem. 2012, 47, 2500-2509. [CrossRef]

91. Gong, Z.; Wang, H.; Tang, J.; Bi, C.; Li, Q.; Zhang, X. Coordinated Expression of Astaxanthin Biosynthesis Genes for Improved Astaxanthin Production in Escherichia coli. J. Agric. Food Chem. 2020, 68, 14917-14927. [CrossRef]

92. Ambati, R.R.; Moi, P.S.; Ravi, S.; Aswathanarayana, R.G. Astaxanthin: Sources, extraction, stability, biological activities and its commercial applications-A review. Mar. Drugs 2014, 12, 128-152. [CrossRef] [PubMed]

93. Muhammad, A.; Feng, X.; Rasool, A.; Sun, W.; Li, C. Production of plant natural products through engineered Yarrowia lipolytica. Biotechnol. Adv. 2020, 43, 107555. [CrossRef]

94. de la Fuente, J.L.; Rodríguez-Sáiz, M.; Schleissner, C.; Díez, B.; Peiro, E.; Barredo, J.L. High-titer production of astaxanthin by the semi-industrial fermentation of Xanthophyllomyces dendrorhous. J. Biotechnol. 2010, 148, 144-146. [CrossRef]

95. Zhou, P.; Xie, W.; Li, A.; Wang, F.; Yao, Z.; Bian, Q.; Zhu, Y.; Yu, H.; Ye, L. Alleviation of metabolic bottleneck by combinatorial engineering enhanced astaxanthin synthesis in Saccharomyces cerevisiae. Enzym. Microb. Technol. 2017, 100, 28-36. [CrossRef]

96. Tramontin, L.R.R.; Kildegaard, K.R.; Sudarsan, S.; Borodina, I. Enhancement of Astaxanthin Biosynthesis in Oleaginous Yeast Yarrowia lipolytica via Microalgal Pathway. Microorganisms 2019, 7, 472. [CrossRef] [PubMed]

97. Shang, M.; Ding, W.; Zhao, Y.; Xu, J.-W.; Zhao, P.; Li, T.; Ma, H.; Yu, X. Enhanced astaxanthin production from Haematococcus pluvialis using butylated hydroxyanisole. J. Biotechnol. 2016, 236, 199-207. [CrossRef]

98. Mao, X.; Wu, T.; Sun, D.; Zhang, Z.; Chen, F. Differential responses of the green microalga Chlorella zofingiensis to the starvation of various nutrients for oil and astaxanthin production. Bioresour. Technol. 2018, 249, 791-798. [CrossRef] [PubMed]

99. Abe, K.; Hattori, H.; Hirano, M. Accumulation and antioxidant activity of secondary carotenoids in the aerial microalga Coelastrella striolata var. multistriata. Food Chem. 2007, 100, 656-661. [CrossRef]

100. Shah, M.M.R.; Liang, Y.; Cheng, J.J.; Daroch, M. Astaxanthin-Producing Green Microalga Haematococcus pluvialis: From Single Cell to High Value Commercial Products. Front. Plant Sci. 2016, 7, 531. [CrossRef]

101. Panis, G.; Carreon, J.R. Commercial astaxanthin production derived by green alga Haematococcus pluvialis: A microalgae process model and a techno-economic assessment all through production line. Algal Res. 2016, 18, 175-190. [CrossRef]

102. Jannel, S.; Caro, Y.; Bermudes, M.; Petit, T. Novel Insights into the Biotechnological Production of Haematococcus pluvialis-Derived Astaxanthin: Advances and Key Challenges to Allow Its Industrial Use as Novel Food Ingredient. J. Mar. Sci. Eng. 2020, 8, 789. [CrossRef]

103. Pan, X.; Wang, B.; Duan, R.; Jia, J.; Li, J.; Xiong, W.; Ling, X.; Chen, C.; Huang, X.; Zhang, G.; et al. Enhancing astaxanthin accumulation in Xanthophyllomyces dendrorhous by a phytohormone: Metabolomic and gene expression profiles. Microb. Biotechnol. 2020, 13, 1446-1460. [CrossRef]

104. Milas, N.A.; Davis, P.; Belič, I.; Fleš, D.A. Synthesis of $\beta$-Carotene. J. Am. Chem. Soc. 1950, 72, 4844. [CrossRef] 
105. Ribeiro, B.D.; Barreto, D.W.; Coelho, M.A.Z. Technological Aspects of $\beta$-Carotene Production. Food Bioprocess Technol. 2011, 4 , 693-701. [CrossRef]

106. Saini, R.K.; Keum, Y.-S. Carotenoid extraction methods: A review of recent developments. Food Chem. 2018, $240,90-103$. [CrossRef] [PubMed]

107. Hu, I.-C. Production of potential coproducts from microalgae. In Biofuels from Algae; Elsevier: Amsterdam, The Netherlands, 2019; pp. 345-358.

108. Huang, W.; Lin, Y.; He, M.; Gong, Y.; Huang, J. Induced High-Yield Production of Zeaxanthin, Lutein, and $\beta$-Carotene by a Mutant of Chlorella zofingiensis. J. Agric. Food Chem. 2018, 66, 891-897. [CrossRef]

109. Massoud, R.; Khosravi-Darani, K. A Review on the Impacts of Process Variables on Microbial Production of Carotenoid Pigments. In Food Biosynthesis; Elsevier: Amsterdam, The Netherlands, 2017; pp. 183-211. ISBN 978-0-12-811372-1.

110. Nanou, K.; Roukas, T.; Papadakis, E. Improved production of carotenes from synthetic medium by Blakeslea trispora in a bubble column reactor. Biochem. Eng. J. 2012, 67, 203-207. [CrossRef]

111. Martínez-Cámara, S.; Rubio, S.; del Río, H.; Rodríguez-Sáiz, M.; Barredo, J.-L. Lycopene production by mated fermentation of Blakeslea trispora. In Microbial Carotenoids; Barreiro, C., Barredo, J., Eds.; Springer Protocols: New York, NY, USA, 2018; pp. 257-268. [CrossRef]

112. Rapoport, A.; Guzhova, I.; Bernetti, L.; Buzzini, P.; Kieliszek, M.; Kot, A.M. Carotenoids and some other pigments from fungi and yeasts. Metabolites 2021, 11, 92. [CrossRef]

113. Barreiro, C.; Barredo, J.-L. (Eds.) Microbial Carotenoids. Methods in Molecular Biology; Springer: New York, NY, USA, 2018; Volume 1852, ISBN 978-1-4939-8741-2.

114. Fernández-Sevilla, J.M.; Acién Fernández, F.G.; Molina Grima, E. Biotechnological production of lutein and its applications. Appl. Microbiol. Biotechnol. 2010, 86, 27-40. [CrossRef]

115. Saha, S.K.; Ermis, H.; Murray, P. Marine Microalgae for Potential Lutein Production. Appl. Sci. 2020, 10, 6457. [CrossRef]

116. Bernstein, P.S.; Li, B.; Vachali, P.P.; Gorusupudi, A.; Shyam, R.; Henriksen, B.S.; Nolan, J.M. Lutein, zeaxanthin, and mesozeaxanthin: The basic and clinical science underlying carotenoid-based nutritional interventions against ocular disease. Prog. Retin. Eye Res. 2016, 50, 34-66. [CrossRef]

117. Liu, J.; Gerken, H.; Huang, J.; Chen, F. Engineering of an endogenous phytoene desaturase gene as a dominant selectable marker for Chlamydomonas reinhardtii transformation and enhanced biosynthesis of carotenoids. Process Biochem. 2013, 48, 788-795. [CrossRef]

118. Rathod, J.P.; Vira, C.; Lali, A.M.; Prakash, G. Metabolic Engineering of Chlamydomonas reinhardtii for Enhanced $\beta$-Carotene and Lutein Production. Appl. Biochem. Biotechnol. 2020, 190, 1457-1469. [CrossRef] [PubMed]

119. Chen, J.-H.; Chen, C.-Y.; Hasunuma, T.; Kondo, A.; Chang, C.-H.; Ng, I.-S.; Chang, J.-S. Enhancing lutein production with mixotrophic cultivation of Chlorella sorokiniana MB-1-M12 using different bioprocess operation strategies. Bioresour. Technol. 2019, 278, 17-25. [CrossRef]

120. Molino, A.; Mehariya, S.; Karatza, D.; Chianese, S.; Iovine, A.; Casella, P.; Marino, T.; Musmarra, D. Bench-Scale Cultivation of Microalgae Scenedesmus almeriensis for $\mathrm{CO}_{2}$ Capture and Lutein Production. Energies 2019, 12, 2806. [CrossRef]

121. Chen, W.-C.; Hsu, Y.-C.; Chang, J.-S.; Ho, S.-H.; Wang, L.-F.; Wei, Y.-H. Enhancing production of lutein by a mixotrophic cultivation system using microalga Scenedesmus obliquus CWL-1. Bioresour. Technol. 2019, 291, 121891. [CrossRef]

122. Blanco, A.M.; Moreno, J.; Del Campo, J.A.; Rivas, J.; Guerrero, M.G. Outdoor cultivation of lutein-rich cells of Muriellopsis sp. in open ponds. Appl. Microbiol. Biotechnol. 2007, 73, 1259-1266. [CrossRef]

123. Cámara, M.; de Cortes Sánchez-Mata, M.; Fernández-Ruiz, V.; Cámara, R.M.; Manzoor, S.; Caceres, J.O. Lycopene: A Review of Chemical and Biological Activity Related to Beneficial Health Effects. In Studies in Natural Products Chemistry; Elsevier B.V.: Amsterdam, The Netherlands, 2013; Volume 40, pp. 383-426. [CrossRef]

124. Ciriminna, R.; Fidalgo, A.; Meneguzzo, F.; Ilharco, L.M.; Pagliaro, M. Lycopene: Emerging Production Methods and Applications of a Valued Carotenoid. ACS Sustain. Chem. Eng. 2016, 4, 643-650. [CrossRef]

125. Shi, B.; Ma, T.; Ye, Z.; Li, X.; Huang, Y.; Zhou, Z.; Ding, Y.; Deng, Z.; Liu, T. Systematic Metabolic Engineering of Saccharomyces cerevisiae for Lycopene Overproduction. J. Agric. Food Chem. 2019, 67, 11148-11157. [CrossRef]

126. Luo, Z.; Liu, N.; Lazar, Z.; Chatzivasileiou, A.; Ward, V.; Chen, J.; Zhou, J.; Stephanopoulos, G. Enhancing isoprenoid synthesis in Yarrowia lipolytica by expressing the isopentenol utilization pathway and modulating intracellular hydrophobicity. Metab. Eng. 2020, 61, 344-351. [CrossRef]

127. Hameed, A.; Arun, A.B.; Ho, H.-P.; Chang, C.-M.J.; Rekha, P.D.; Lee, M.-R.; Singh, S.; Young, C.-C. Supercritical Carbon Dioxide Micronization of Zeaxanthin from Moderately Thermophilic Bacteria Muricauda lutaonensis CC-HSB-11 T. J. Agric. Food Chem. 2011, 59, 4119-4124. [CrossRef]

128. Zhang, Y.; Liu, Z.; Sun, J.; Xue, C.; Mao, X. Biotechnological production of zeaxanthin by microorganisms. Trends Food Sci. Technol. 2017, 71, 225-234. [CrossRef]

129. Song, I.; Kim, J.; Baek, K.; Choi, Y.; Shin, B.; Jin, E. The generation of metabolic changes for the production of high-purity zeaxanthin mediated by CRISPR-Cas9 in Chlamydomonas reinhardtii. Microb. Cell Fact. 2020, 19, 220. [CrossRef]

130. Beuttler, H.; Hoffmann, J.; Jeske, M.; Hauer, B.; Schmid, R.D.; Altenbuchner, J.; Urlacher, V.B. Biosynthesis of zeaxanthin in recombinant Pseudomonas putida. Appl. Microbiol. Biotechnol. 2011, 89, 1137-1147. [CrossRef] 
131. Larroude, M.; Celinska, E.; Back, A.; Thomas, S.; Nicaud, J.-M.; Ledesma-Amaro, R. A synthetic biology approach to transform Yarrowia lipolytica into a competitive biotechnological producer of $\beta$-carotene. Biotechnol. Bioeng. 2018, 115, 464-472. [CrossRef]

132. Petrik, S.; Marova, I.; Haronikova, A.; Kostovova, I.; Breierova, E. Production of biomass, carotenoid and other lipid metabolites by several red yeast strains cultivated on waste glycerol from biofuel production-A comparative screening study. Ann. Microbiol. 2013, 63, 1537-1551. [CrossRef]

133. Verwaal, R.; Wang, J.; Meijnen, J.-P.; Visser, H.; Sandmann, G.; van den Berg, J.A.; van Ooyen, A.J.J. High-level production of betacarotene in Saccharomyces cerevisiae by successive transformation with carotenogenic genes from Xanthophyllomyces dendrorhous. Appl. Environ. Microbiol. 2007, 73, 4342-4350. [CrossRef] [PubMed]

134. Gonabadi, E.; Samadlouie, H.R.; Shafafi Zenoozian, M. Optimization of culture conditions for enhanced Dunaliella salina productions in mixotrophic culture. Prep. Biochem. Biotechnol. 2021, 1-9. [CrossRef]

135. Li, H.-B.; Fan, K.-W.; Chen, F. Isolation and purification of canthaxanthin from the microalga Chlorella zofingiensis by high-speed counter-current chromatography. J. Sep. Sci. 2006, 29, 699-703. [CrossRef] [PubMed]

136. Nasri Nasrabadi, M.R.; Razavi, S.H. Use of response surface methodology in a fed-batch process for optimization of tricarboxylic acid cycle intermediates to achieve high levels of canthaxanthin from Dietzia natronolimnaea HS-1. J. Biosci. Bioeng. 2010, 109, 361-368. [CrossRef] [PubMed]

137. Gharibzahedi, S.M.T.; Razavi, S.H.; Mousavi, S.M. Microbial canthaxanthin: Perspectives on biochemistry and biotechnological production. Eng. Life Sci. 2013, 13, 408-417. [CrossRef]

138. Minhas, A.K.; Hodgson, P.; Barrow, C.J.; Sashidhar, B.; Adholeya, A. The isolation and identification of new microalgal strains producing oil and carotenoid simultaneously with biofuel potential. Bioresour. Technol. 2016, 211, 556-565. [CrossRef]

139. Pegklidou, K.; Mantzouridou, F.; Tsimidou, M.Z. Lycopene Production Using Blakeslea trispora in the Presence of 2-Methyl Imidazole: Yield, Selectivity, and Safety Aspects. J. Agric. Food Chem. 2008, 56, 4482-4490. [CrossRef]

140. Hernández-Almanza, A.; Montañez-Sáenz, J.; Martínez-Ávila, C.; Rodríguez-Herrera, R.; Aguilar, C.N. Carotenoid production by Rhodotorula glutinis YB-252 in solid-state fermentation. Food Biosci. 2014, 7, 31-36. [CrossRef]

141. Schwartz, C.; Frogue, K.; Misa, J.; Wheeldon, I. Host and Pathway Engineering for Enhanced Lycopene Biosynthesis in Yarrowia lipolytica. Front. Microbiol. 2017, 8, 2233. [CrossRef] [PubMed]

142. Nasri Nasrabadi, M.R.; Razavi, S.H. High levels lycopene accumulation by Dietzia natronolimnaea HS-1 using lycopene cyclase inhibitors in a fed-batch process. Food Sci. Biotechnol. 2010, 19, 899-906. [CrossRef]

143. Fazeli, M.R.; Tofighi, H.; Madadkar-Sobhani, A.; Shahverdi, A.R.; Nejad-Sattari, T.; Mirzaie, S.; Jamalifar, H. Nicotine inhibition of lycopene cyclase enhances accumulation of carotenoid intermediates by Dunaliella salina CCAP 19/18. Eur. J. Phycol. 2009, 44, 215-220. [CrossRef]

144. Zhang, X.; Wang, D.; Duan, Y.; Zheng, X.; Lin, Y.; Liang, S. Production of lycopene by metabolically engineered Pichia pastoris. Biosci. Biotechnol. Biochem. 2020, 84, 463-470. [CrossRef]

145. Papp, T.; Velayos, A.; Bartók, T.; Eslava, A.P.; Vágvölgyi, C.; Iturriaga, E.A. Heterologous expression of astaxanthin biosynthesis genes in Mucor circinelloides. Appl. Microbiol. Biotechnol. 2006, 69, 526-531. [CrossRef]

146. Asker, D.; Beppu, T.; Ueda, K. Mesoflavibacter zeaxanthinifaciens gen. nov., sp. nov., a novel zeaxanthin-producing marine bacterium of the family Flavobacteriaceae. Syst. Appl. Microbiol. 2007, 30, 291-296. [CrossRef]

147. Hameed, A.; Shahina, M.; Lin, S.-Y.; Sridhar, K.R.; Young, L.-S.; Lee, M.-R.; Chen, W.-M.; Chou, J.-H.; Young, C.-C. Siansivirga zeaxanthinifaciens gen. nov., sp. nov., a novel zeaxanthin-producing member of the family Flavobacteriaceae isolated from coastal seawater of Taiwan. FEMS Microbiol. Lett. 2012, 333, 37-45. [CrossRef]

148. Thawornwiriyanun, P.; Tanasupawat, S.; Dechsakulwatana, C.; Techkarnjanaruk, S.; Suntornsuk, W. Identification of Newly Zeaxanthin-Producing Bacteria Isolated from Sponges in the Gulf of Thailand and their Zeaxanthin Production. Appl. Biochem. Biotechnol. 2012, 167, 2357-2368. [CrossRef] [PubMed]

149. Issouf, M.; Mearns, S.A.; Fraser, K.A.; Hodgson, R. Biological production of Zeaxanthin. European Patent Application No. EP1893769B1, 2012.

150. Joshi, C.; Singhal, R.S. Modelling and optimization of zeaxanthin production by Paracoccus zeaxanthinifaciens ATCC 21588 using hybrid genetic algorithm techniques. Biocatal. Agric. Biotechnol. 2016, 8, 228-235. [CrossRef]

151. Ram, S.; Tirkey, S.R.; Kumar, M.A.; Mishra, S. Ameliorating process parameters for zeaxanthin yield in Arthrobacter gandavensis MTCC 25325. AMB Express 2020, 10, 69. [CrossRef] 